
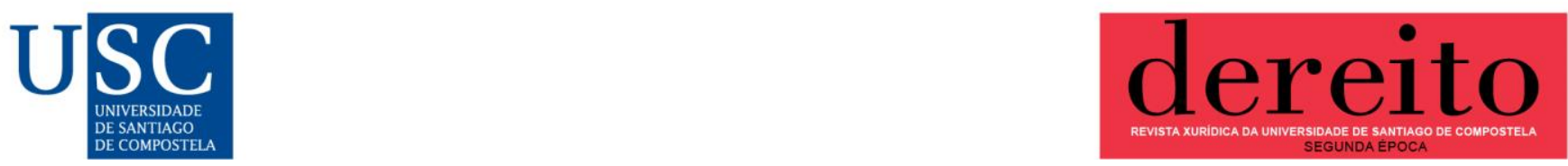

Dereito: revista xurídica da Universidade de Santiago de Compostela, 30 (1), 2021. ISSN: 2174-0690

https://doi.org/10.15304/dereito.30.1.7515

Estudios

\title{
Evolución histórica del desempleo en el derecho originario de la Unión Europea ${ }^{1}$
}

Unemployment historical evolution in the primary European Union Law

José Manuel Pazó Argibay

Universidad de Santiago de Compostela, España

josemanuel.pazo@usc.es

\section{Resumen}

Muchos de los aspectos que, hoy en día, configuran la protección por desempleo en el Derecho de la Unión Europea no serían comprensibles sin un conocimiento previo de la evolución histórica de esta contingencia. Este trabajo ofrece un estudio pormenorizado de la evolución en el tratamiento del desempleo en el derecho originario de la Unión Europea, partiendo de unos inicios de ausencia absoluta a la preocupación máxima de los últimos años, identificando las bases históricas, sociales, económicas y políticas sobre las que se asienta su regulación actual.

Palabras clave: Unión Europea; Desempleo; Política Social; Seguridad Social.

\section{Abstract}

The aspects that configure unemployment protection in European Union Law wouldn't be understandable without prior knowledge of its historical evolution. This paper offers a detailed study about the developing of unemployment protection in the European Union, starting from the beginnings, of absolute absence, to the maximum interest in recent years, identifying the historical, social, economic and political bases of its current regulation.

Keywords: European Union; Unemployment; Social Policy; Social Security 


\section{ANTECEDENTES SOCIALES PREVIOS AL TRATADO DE PARÍS}

En el análisis de los antecedentes, o actos previos, que dieron origen a lo que hoy conocemos como Unión Europea, aunque intento fallido, debe partirse de la figura de Aristide Briand, ministro de Asuntos Exteriores francés. Este, ya en el año 1929, utilizó el término Unión Europea o Asociación Europea para referirse a una propuesta de unión y cooperación entre los Estados europeos $^{2}$. Si bien la coyuntura económica, política y social de la época, recién terminada la Primera Guerra Mundial, no favoreció la maduración de esta propuesta, es idea común que fue su exposición ante la Sociedad de Naciones la primera ocasión en la que públicamente se abogó y propuso una unión para la cooperación entre los Estados europeos ${ }^{3}$.

Resulta también reseñable el Plan de Ayuda a Europa, conocido con el Plan Marshall ${ }^{4}$, no sólo por la importante inyección económica que supuso para la devastada Europa, sino porque sería también el germen de la futura Organización Europea de Cooperación Económica, organización creada para la canalización y gestión del dinero proveniente de EEUU 5 . En su discurso explicativo del plan económico para Europa en la Universidad de Harvard (1947), Marshall abogó por restaurar la confianza de los europeos en el futuro económico de sus propios países y de Europa como un todo, partiendo de la necesidad de que tiene que haber un acuerdo entre los países de Europa para dirigir su propia reconstrucción de la mano, y con el apoyo económico, de los EE.UU. En su discurso, Marshall hizo suya la denominación Estados Unidos de Europa que ya un año antes había utilizado W. Churchill, si bien dio total autonomía de denominación y estructura a los Estados de Europa, cualesquiera que sean el nombre y la forma que tomen.

El Plan Marshall fue un instrumento crucial para la recuperación europea durante la segunda postguerra. Supuso la plataforma para el despegue económico europeo y sirvió para establecer las primeras pautas de cooperación entre los Estados amparados por él ${ }^{6}$. Esta cooperación inicial no fue, ni mucho menos, voluntaria, sino que venía contemplada en el propio Plan, que exigía cierta coordinación entre los Estados beneficiarios para el reparto, organización y control de la aportación económica norteamericana? ${ }^{7}$.

Para dar forma a esta exigencia, en abril de 1948 tuvo lugar la Conferencia de París y, fruto de esta, el Tratado de París, que daría lugar a la Organización Europea de Cooperación Económica como primer instrumento formal de cooperación entre los Estados europeos ${ }^{8}$. La OECE no nacía solo con la idea de servir como herramienta para el reparto de la ayuda económica americana, sino que sus objetivos eran mucho más ambiciosos, intentando favorecer los intercambios entre los Estados europeos, combatir restricciones, eliminar las barreras aduaneras y, en resumen, crear hábitos de cooperación internacional ${ }^{9}$. Con todo, a pesar de lo ambicioso y novedoso de este primer instrumento de cooperación, su contenido social era prácticamente inexistente y se limitaba a favorecer el movimiento de trabajadores entre los Estados firmantes a través de uno de los comités técnicos creados en su seno.

El antecedente de mayor importancia para la creación de la futura Unión Europea fue la Conferencia de La Haya, en 1948, ampliamente considerada como el germen que posteriormente daría lugar al Consejo de Europa ${ }^{10}$. Sus conclusiones se plasmaron en una serie de resoluciones política, cultural, económica y social- aceptadas y asumidas como punto de partida. Fue en estas resoluciones, en concreto, en la resolución económica y social, fue donde por primera vez se plasmaron una serie de objetivos, si bien genéricos, en materia social, inexistentes hasta ese momento ${ }^{11}$. Debe recordarse que todos los acuerdos celebrados hasta el momento tuvieron un 
marcado carácter político y económico, quedando el aspecto social completamente al margen. El Congreso de La Haya supuso un avance al respecto al introducir una resolución, si bien meramente propositiva, con contenido social. En el apartado 5.d.i de la resolución se puso de manifiesto la necesidad de aumentar en la mayor medida posible el nivel de vida de las poblaciones de Europa, adoptando medidas destinadas a aumentar la producción, pero invitando a participar en la planificación y puesta en marcha de estas medidas a las asociaciones profesionales, económicas y sociales de los distintos países, en una novedosa apuesta por la participación social en aras de mejorar las condiciones sociales.

El bloque social más importante se incluyó en el apartado 5.d.ii de la resolución, en el que se recogió la necesidad de promover medidas que favoreciesen la movilidad de la mano de obra en la mayor medida posible, asegurando a los trabajadores migrantes y a sus familias las normas de salarios, seguridad social, condiciones de vida y condiciones de empleo que prevalecen en el país al que vienen. Podría decirse, sin apenas discusión, que este párrafo de la resolución económica y social de la Conferencia de La Haya contenía la esencia misma del derecho social de la Unión Europea en tanto que proponía medidas que pretendían garantizar la libre circulación de los trabajadores y sus familias, eje central para una verdadera unión entre los Estados.

En sus objetivos finales, la resolución contempló también en su apartado 6.e) la coordinación de la legislación social como medio necesario para poder dar cumplimiento a su contenido social. Además de estas materias directamente contempladas, se establecieron también una serie de cuestiones sociales para su futuro estudio, como por ejemplo el establecimiento de una Comisión de Emigración para organizar la migración en Europa, la disparidad de salarios y condiciones de empleo, las contribuciones económicas y sociales para el cumplimiento del Plan Marshall, etc.

Finalmente, desde la celebración del Congreso de La Haya se llevaron a cabo una serie de tímidos movimientos que dieron lugar a la firma del Pacto de Bruselas el 17 de Marzo de 1948. Aunque su contenido y finalidad fueron, principalmente, de apoyo político y militar, contenía también algunas ideas básicas de colaboración económica y social entre los cinco países firmantes ${ }^{12}$ : Bélgica, Francia, Holanda, Luxemburgo y el Reino Unido.

Amparados por este Pacto, los respectivos ministros de asuntos exteriores se reunieron en forma de Consejo Consultivo y promovieron la creación del Comité para el Estudio y Desarrollo de la Unión Europea ${ }^{13}$. No sin discrepancias previas en cuanto a su naturaleza y competencias, los cinco acordaron la creación del Consejo de Europa, en apariencia un solo órgano, si bien en la práctica suponía la creación de un Comité de Ministros y una Asamblea Consultiva14.

Los Estatutos del Consejo de Europa se componían de un preámbulo y 42 artículos de marcado carácter y contenido político. Su contenido social, meramente testimonial, apenas aparecía en el artículo 1 de una manera genérica y sin determinación de aspectos o acciones concretas al respecto. Así, en este artículo 1, en el que se abordaba la finalidad del Consejo de Europa, se hacía una vaga mención a favorecer el progreso económico y social y a la conclusión de acuerdos y la adopción de una acción conjunta en varios campos, entre ellos, el social ${ }^{15}$.

A pesar de su escasa iniciativa social, al menos inicialmente, uno de los mayores logros del Consejo de Europa en este ámbito sería la Convención Europea de los Derechos del Hombre, celebrada en Noviembre de 1950 y que sentó los cimientos de la Carta Social Europea16. Firmada en octubre de 1961 y con meros efectos declarativos ${ }^{17}$, la Carta contenía una serie de objetivos o principios sociales que los Estados miembros asumían como comunes ${ }^{18}$. Así, recogía como 
objetivos comunes de los Estados el derecho a la libre elección y desarrollo del trabajo, unas condiciones de trabajo equitativas, el derecho a la seguridad e higiene en el trabajo, el derecho a la negociación colectiva, la protección de la maternidad, el derecho a la formación y orientación profesional, el derecho a la Seguridad Social ${ }^{19}$, etc. En relación con el desempleo, la Carta contenía, en su artículo 1, una serie de disposiciones con un claro componente de políticas activas de empleo. En su apartado primero, reconocía como uno de sus principales objetivos la obtención y el mantenimiento del nivel más elevado y estable posible del empleo, con la vista puesta en lograr el pleno empleo. A este respecto, los apartados tercero y cuarto abogaban por el establecimiento de servicios gratuitos de empleo para todos los trabajadores ${ }^{20}$, así como la promoción de la orientación, la formación y la readaptación profesional.

\section{DEL TRATADO DE PARÍS AL TRATADO DE ROMA}

\subsection{La cuestión social y el desempleo en el Tratado de París}

La Declaración Schuman, del 9 de mayo de 1950, considerada como la partida de nacimiento de la Unión Europea ${ }^{21}$, contenía la hoja de ruta básica para la creación de la Nueva Autoridad que se pretendía crear para unificar la producción franco-alemana de carbón y de acero. Si bien inicialmente estaba pensada para aunar a ambos países, su redacción dejaba abierta la adhesión de los demás países europeos.

Atendiendo a su contenido social, apenas abordado dado el marcado carácter industrial y económico del documento, se limitaba a establecer la equiparación y mejora de las condiciones de vida de los trabajadores de estas industrias, dejando, una vez más, el aspecto social en un segundo plano.

Con la intención de no dejar enfriar la buena aceptación que había tenido la Declaración Schuman, el 18 de Abril de 1951 se firmaría en París el Tratado por el que se creaba la Comunidad Europea del Carbón y del Acero. Se materializaba de esta forma el acuerdo más completo y, a la vez, más concreto, de cuantos se habían celebrado hasta el momento.

El Tratado de la Comunidad Europea del Carbón y del Acero consiguió plasmar sobre el papel una serie de propuestas que, aun no siendo novedosas y estando limitadas a un sector muy concreto, supusieron un importante avance con respecto a todos los intentos anteriores. Con un preámbulo y cien artículos se puso en marcha la primera Comunidad Europea. Las ideas en torno a una Europa organizada, la mejora del nivel de vida o el desarrollo económico común aparecieron reflejadas ya en el propio preámbulo en el que, además, se hizo una mención expresa a la puesta en marcha de instituciones capaces de orientar hacia un destino en adelante compartido.

Tal y como fue concebido, el articulado del Tratado estaba principalmente orientado a regular una nueva Comunidad, si bien su objeto era muy concreto y determinado. En materia social, el TCECA reflejó un tímido avance con respecto a otros intentos anteriores, si bien, como ya se indicó, únicamente era aplicable al sector del carbón y del acero 22 .

La primera referencia de contenido social del TCECA aparecía en su artículo 2 en el que, entre las finalidades que se establecían para la Comunidad, se hacía mención al desarrollo del empleo y a una distribución racional de la producción con el fin de garantizar la continuidad en el empleo. 
El artículo 3 TCECA encomendaba a las instituciones de la Comunidad, en su epígrafe e), la promoción y mejora de las condiciones de vida y de trabajo de los trabajadores.

El artículo 46 TCECA daba protagonismo por primera vez a la participación de los agentes sociales en relación con la posibilidad de plantear sugerencias u observaciones sobre las cuestiones que les afectaban. Esta participación se establecía en el TCECA de manera bidireccional. La Alta Autoridad podía someter a su consulta aquellas cuestiones que podrían afectarles y, al mismo tiempo, sin esta consulta previa, los agentes sociales estaban facultados para proponer a la Alta Autoridad toda clase de sugerencias. Además, el TCECA reconocía un extenso abanico de agentes interesados, acogiendo expresamente en el párrafo primero del artículo 46 no solo a empresarios y trabajadores, sino también a usuarios y comerciantes, a sus asociaciones, así como a cualquier perito.

En este marco, la Alta Autoridad tenía encomendadas distintas tareas, como el estudio de las posibilidades de obtener un nuevo empleo para aquellos trabajadores que se encontraban en situación de desempleo por las exigencias del mercado o las transformaciones técnicas. De esta manera, la cuestión del desempleo entraba por primera vez en el texto de un Tratado, si bien lo hacía tímidamente, de manera indirecta y a través de una línea de acción muy concreta. Así, la acción sobre el desempleo que contemplaba el TCECA se limitaba a simples tareas de análisis y búsqueda de opciones de nueva ocupación en las industrias existentes o la creación de nuevas actividades donde dar cabida a los trabajadores desempleados. Cabe señalar que en el texto no se mencionaba el término desempleo, echando mano de una redacción más positiva utilizando expresiones como reempleo o mano de obra que hubiere quedado disponible para referirse a esta situación. A pesar de la dócil redacción empleada y del grado de normalidad que intentaba darse a esta situación, ligándola directamente con la evolución del mercado o a las transformaciones técnicas, y a su escaso alcance de estudio de las posibilidades de reempleo, no puede obviarse la importancia de esta primera presencia de la cuestión del desempleo en el Tratado. Por otro lado, el artículo 46 TCECA encomendaba también a la Alta Autoridad una tarea de análisis y estudio continuo de las condiciones de vida y trabajo de los trabajadores bajo su campo de aplicación.

Con todo, el bloque social más importante del TCECA aparecía densamente recogido en sus artículos 68 y 69 (Capítulo VIII del Título Tercero). El artículo 68 TCECA se encargaba de establecer las directrices en materia de salarios, mientras que el artículo 69 TCECA hacía lo propio en relación con el movimiento de trabajadores.

El artículo 68 TCECA comenzaba por reconocer la autonomía e independencia de los Estados miembros en relación con la fijación de los salarios y las prestaciones sociales, dejándolos al margen de su campo de aplicación. Es decir, permitía a los Estados seguir con sus sistemas de fijación en estas cuestiones, conocedores de la reticencia de algunos de ellos a hacer concesiones en determinadas materias. Ahora bien, la Alta Autoridad se reservaba en el propio artículo 68 TCECA una posición in vigilando con la posibilidad de intervenir ante salarios anormalmente bajos por medio de recomendaciones a empresas o Gobiernos. Esa posición in vigilando se recogía también en el artículo 68.3 TCECA al encomendar a la Alta Autoridad una función de control de la calidad de vida de los trabajadores ante reducciones en su salario y, a su vez, que estas reducciones de salario no fueran utilizadas como mecanismo habitual de ajuste económico de las empresas. La intervención de la Alta Autoridad en esta situación era nuevamente una recomendación en el sentido de asegurar, a cargo de las empresas, beneficios a la mano de obra que compensen esta reducción ${ }^{23}$. 
El artículo 68.4 TCECA establecía, a su vez, la obligatoriedad de notificación a la Alta Autoridad de cualquier reducción salarial que afectase al conjunto o a una parte notable de una empresa.

Finalmente, pese a optar por las recomendaciones como vía suave de intervención para reajustar aspectos salariales, el apartado 6 del artículo 68 TCECA establecía la potestad sancionadora de la Alta Autoridad en esta materia al contemplar la posibilidad de sancionar con multas a las empresas que no se atuvieran a las recomendaciones. El límite máximo de la sanción no podría exceder del doble de los ahorros en el coste de mano de obra indebidamente realizados. Debe puntualizarse también que esta potestad sancionadora de la Alta Autoridad estaba dirigida únicamente a las empresas incumplidoras, eximiendo de cualquier tipo de sanción a los Gobiernos incumplidores.

Por su parte, el artículo 69 TCECA abordaba todas las cuestiones relativas a los movimientos de mano de obra. El contenido de este artículo puede considerarse el punto de partida de lo que en un futuro sería la libre circulación de trabajadores ${ }^{24}$.

En su apartado 1, el artículo 69 TCECA eliminaba cualquier tipo de restricción por motivos de nacionalidad con respecto a cualquier cuestión de empleo, eso sí, en consonancia con el objeto del Tratado, limitada a los sectores del carbón y del acero ${ }^{25}$. En su apartado 2, se encomendaba a los Estados la tarea de establecer una definición común de especialidades y condiciones de capacitación a efectos de favorecer el movimiento de mano de obra entre Estados sin ningún tipo de restricción. Al mismo tiempo, y en relación con lo anterior, se hacía hincapié en la necesidad de articular procedimientos técnicos que permitieran poner en relación la oferta y la demanda de empleo entre los distintos Estados. A pesar de lo poco preciso de esta disposición, lo cierto es que se contemplaba ya la puesta en marcha de mecanismos que bien podrían considerarse políticas activas contra el desempleo, buscando un mayor ajuste entre oferta y demanda de empleo dentro de la Comunidad.

El artículo 69 TCECA contenía también, en su apartado 3, indicaciones con respecto a situaciones de mano de obra cualificada insuficiente. En este sentido, recomendaba a los Estados miembros la revisión de su normativa en materia de inmigración y la adopción de medidas que favorecieran el reempleo de trabajadores de otros Estados miembros ${ }^{26}$.

Ahondando un poco más en el principio de no discriminación por razón de nacionalidad, el apartado 4 recogía expresamente la prohibición de discriminación en la retribución y las condiciones de trabajo entre trabajadores nacionales y trabajadores de otros Estados. Dando un paso más, el apartado 4 del artículo 69 TCECA encomendaba también a los Estados la adopción de las medidas necesarias a fin de que las disposiciones relativas a la seguridad social no constituyan un obstáculo para los movimientos de la mano de obra, indicación que podría entenderse como un primer guiño a la futura coordinación de los sistemas de Seguridad Social de los Estados miembros. Contemplaba también este apartado 4 la necesidad del establecimiento de medidas específicas para los trabajadores fronterizos, para quienes la dualidad Estado de residencia vs. Estado de empleo hizo necesario, posteriormente, el desarrollo de disposiciones particulares en materia de desempleo de aplicación a este colectivo de trabajadores.

Como conclusión, aunque tímidos y referidos únicamente a la industria del carbón y del acero, debe reconocerse que el Tratado de la Comunidad Europea del Carbón y del Acero supuso ciertos avances de contenido social en comparación con todos los intentos equiparables previos ${ }^{27}$. Así, como se ha visto, el texto abogaba por la puesta en marcha de acciones para la mejora de las 
condiciones de vida de los trabajadores (artículo 3) dando participación a los agentes sociales en la puesta en marcha de las mismas (artículo 46). Por su parte, los artículos 68 y 69 TCECA recogían, aunque de una manera muy inicial y poco desarrollada, los elementos esenciales de la actual Unión Europea, la prohibición de discriminación por razón de nacionalidad y la libre circulación de trabajadores. Además, como refuerzo al incipiente contenido social recogido en el propio Tratado, la Alta Autoridad asumía también las recomendaciones de la Organización Internacional del Trabajo ${ }^{28}$.

\subsection{El Informe Spaak}

En un nuevo proceso de relanzamiento europeo tuvo especial relevancia la conferencia de ministros exteriores celebrada en Messina en junio de 1955, fruto de la cual vio la luz una resolución, conocida como la Declaración de Messina, que sentaría las bases para una completa integración europea. En materia social, esta Declaración planteaba la necesidad de abordar cuestiones como la armonización de las políticas generales, entre otras, en el ámbito social, el establecimiento de la libre circulación de trabajadores o la armonización de las reglamentaciones en materia social. La conferencia de Messina dio lugar también a la creación de un Comité, presidido por Henri Spaak, que tendría como misión la puesta en marcha sobre el papel de una Unión Económica General y otra más específica en el campo de la energía atómica. Cerca de un año después de la Conferencia de Messina, el comité hacía público el conocido como Informe Spaak, que sería adoptado como base para la redacción del futuro Tratado ${ }^{29}$.

La principal aportación del Informe Spaak al espectro social estaba contenida en sus Títulos II y III. El Título II, en concreto en su Capítulo 2, estaba dedicado a la corrección de distorsiones y a la armonización de las distintas legislaciones nacionales. En la Sección 1ํㅡ se establecía el mecanismo para corregir distorsiones de cualquier tipo, incluidas las laborales, que afectasen o alterasen la libre competencia. Aunque el Informe encomendaba esta tarea a los Gobiernos, dejaba claramente abierta a la participación social para aquellas que se referían a las condiciones laborales. Por su parte, la Sección $2^{\text {a }}$ recogía la necesidad de armonizar las legislaciones nacionales ante posibles desigualdades, aunque estas no provocasen distorsión alguna, especialmente en cuestiones como la equiparación salarial entre hombres y mujeres, la duración de la jornada de trabajo o la duración de las vacaciones pagadas.

El Título III, en su Capítulo 2, recogía la creación de un fondo de readaptación, creado con aportaciones de los Estados miembros, calculadas en función de los salarios y que respondería ante situaciones de desempleo garantizando los beneficios de Seguridad Social básicos. Estas situaciones (cierre de empresa, reducción en la producción, reconversión, etc.) y las coberturas asumidas por el fondo (pagos por cambio de domicilio provocado por situación de desempleo, gastos de formación o habilitación para nuevos trabajos, etc.) aparecían recogidas en el propio documento, poniendo las bases de lo que en el futuro sería el Fondo Social Europeo. Así, por ejemplo, se establecían medidas de apoyo económico para el pago de los salarios en los casos de despido o reducción temporal de trabajadores por empresas en reconversión.

La cuestión central del proceso de integración europea, la libre circulación de trabajadores, tenía también cabida en el Informe Spaak, concretamente en el Capítulo 3 del Título III, referido por completo al libre movimiento de mano de obra ${ }^{30}$. Se establecía como punto de partida la premisa general de que cada Estado incrementaría anualmente el número de trabajadores de otros 
Estados que estuviera en condiciones de emplear, fijando incluso fórmulas para su cálculo. Con todo, el texto también encomendaba a la Comisión la implementación de las medidas necesarias para evitar que estas llegadas de mano de obra pudieran llegar a afectar a las condiciones de vida y de empleo de los trabajadores de un sector determinado. Por otro lado, el Informe, en aras de garantizar la no discriminación por razón de nacionalidad, planteaba la necesidad de acortar progresivamente los períodos de espera de los trabajadores extranjeros para poder optar a determinados puestos.

Sin embargo, el punto donde más claramente se manifestaría esta prohibición de no discriminación por razón de nacionalidad, sería en la letra d) del Capítulo 3 del Título III, al recoger que la Comisión propondría a los Estados medidas para la progresiva eliminación de cualquier tipo de regulación discriminatoria y que, en base a la nacionalidad, otorgase un trato más favorable a los nacionales frente a trabajadores llegados de otros Estados, incluido, el derecho a acceder a una profesión liberal y a ejercerla en el país acogedor.

\subsection{El contenido social del Tratado de Roma}

Cerca de dos años después de la Conferencia de Messina, en marzo de 1957, Francia, Bélgica, Alemania, Italia, Luxemburgo y los Países Bajos darían, de manera formal, un paso más en el proyecto de integración europea firmando los Tratados de Roma, decididos a, como se recogía en la exposición de motivos del TCEE asegurar, mediante una acción común, el progreso económico y social de sus respectivos países, eliminando las barreras que dividen Europa. La firma de ambos Tratados, principalmente, el TCEE, suponía ampliar las experiencias de la CECA a un ámbito más general, es decir, sin limitaciones o sectores de acción concretos ${ }^{31}$.

Con carácter general, el TCEE nacía con la finalidad de mejorar las condiciones de vida y trabajo y, si bien tenía un carácter claramente económico ${ }^{32}$, daba un paso más hacia delante en cuanto a su contenido social ${ }^{33}$. Prueba de esto era el hecho de que no había que adentrarse mucho más allá de su preámbulo para encontrar la primera manifestación al respecto, fijando como fin esencial de la CEE la constante mejora de las condiciones de vida y de trabajo de sus pueblos. Dentro del propio articulado del Tratado, si bien no eran ideas novedosas, el artículo 3 enumeraba acciones de la nueva comunidad encaminadas a la supresión de obstáculos a la libre circulación de personas ${ }^{34}$ y servicios (artículo 3.c) o la aproximación de las legislaciones nacionales en la medida necesaria para el funcionamiento del mercado común (artículo 3.h) ${ }^{35}$. Era en este artículo 3 del TCEE, en concreto en su apartado i), donde se encontraba la primera medida concreta, y novedosa hasta la fecha, en materia social al establecer la creación del Fondo Social Europeo, instrumento pensado para mejorar las posibilidades de empleo de trabajadores y trabajadoras y que iba a ser desarrollado en profundidad en los artículos 123 y siguientes del propio TCEE.

El primer aspecto social que contenía el TCEE, aunque no novedoso ${ }^{36}$, era el relativo a la libre circulación de trabajadores, al que el Tratado dedicaba los cuatro artículos del Capítulo I, dentro del Título III. En el artículo 48 del TCEE, sin perjuicio de las limitaciones justificadas por razones de orden, seguridad y salud pública, se aseguraba la libre circulación de trabajadores dentro de la Comunidad, al tiempo que se eliminaba cualquier tipo de discriminación por razón de nacionalidad con respecto al empleo, la retribución y cualquier otra condición de trabajo ${ }^{37}$. Además de esta consideración de tipo genérico, el apartado 3 del artículo 48 TCEE concretaba un poco más el contenido efectivo de este derecho de libre circulación al garantizar la libre circulación a efectos 
de responder a ofertas efectivas de trabajo, de desplazarse a tal fin por el territorio de los Estados miembros, de residir en el territorio de un Estado miembro con el fin de ejercer en él un empleo e, incluso una vez finalizado este, a permanecer en el territorio de ese Estado miembro. Todos estos derechos concretos en materia de empleo estaban garantizados a los trabajadores de cualquier Estado miembro, con la única excepción, ya señalada, amén de las limitaciones por cuestiones de orden, seguridad y salud pública, de los empleos en la administración pública. Si bien la libre circulación de trabajadores no era una medida original, su tratamiento en el TCEE avanzaba un poco más sobre lo planteado en el TCECA al incrementar su efectividad por dos vías. Por un lado, asegurando la libertad de circulación a todos los trabajadores en general, sin atender a cualificación o sector en concreto y, por otro, encomendando al Consejo (y no a los Estados miembros, como recogía el TCECA) la adopción de las medidas necesarias para su consecución. Sin desmerecer su transcendencia social, debe repararse en que el TCEE aseguraba la libre circulación de trabajadores, no de personas, lo que reforzaba la finalidad marcadamente económica del Tratado al facilitar únicamente el flujo de un recurso económico importante como era el de la mano de obra ${ }^{38}$.

En este sentido, el artículo 49 TCEE encomendaba directamente al Consejo la puesta en marcha, recurriendo a instrumentos del Derecho derivado, de las medidas necesarias para hacer efectiva la libre circulación de trabajadores. El propio artículo 49 TCEE establecía como cuestiones prioritarias la articulación de medidas que asegurasen una estrecha colaboración entre las administraciones laborales de los Estados miembros, medidas tendentes a la eliminación de procedimientos o plazos de carácter laboral de los Estados miembros y que obstaculizasen o impidiesen una libre circulación efectiva de los trabajadores, así como medias encaminadas a eliminar cualquier condición o requisito establecido en la legislación de un Estado miembro y que impusiera a los trabajadores de otros Estados condiciones de acceso al empleo distintas a las requeridas para los trabajadores nacionales.

Por su parte, el artículo 50 TCEE, tan breve como inconcreto, promovía el intercambio de trabajadores jóvenes entre los Estados miembros, en el marco de un genérico programa común.

Como cierre a este primer bloque de contenido social del TCEE, el artículo 51 establecía cuestiones concretas sobre las cuales se hacía necesaria la coordinación de las legislaciones nacionales. Si bien la idea de la coordinación de legislaciones era un tema recurrente en instituciones o declaraciones precedentes ${ }^{39}$, será en el TCEE donde se establezcan por primera vez ámbitos o materias concretas para la coordinación de las legislaciones de los Estados miembros. En este caso, mediante la adopción de medidas que garantizasen la acumulación de todos los períodos tomados en consideración por las distintas legislaciones nacionales para adquirir y conservar el derecho a las prestaciones sociales, así como para el cálculo de estas y para el pago de las prestaciones a las personas que residan en los territorios de los Estados miembros. Los promotores del TCEE eran conscientes de que la libre circulación de trabajadores que se aseguraba en el artículo 48 TCEE no sería del todo efectiva si no se garantizaban los derechos de los trabajadores que decidían ejercerla. La pérdida de los derechos adquiridos, o aquellos en vía de adquisición para el futuro, podían verse en peligro por el ejercicio de la libre de circulación y, por tanto, debían establecerse mecanismos que contemplasen estas situaciones y que no limitasen, aunque indirectamente, la libre circulación. A este respecto, el propio Tratado encomendaba al Consejo la puesta en marcha de medidas que garantizaran la acumulación de los periodos de 
cotización adquiridos en los distintos Estados, a efectos de obtención de prestaciones sociales y su cálculo, así como a su percepción ${ }^{40}$.

El interés por la armonización de las legislaciones nacionales aparecía en un segundo bloque de contenido social del Tratado, esta vez en el Título III, formado por dos capítulos que contenían doce artículos bajo el epígrafe común de política social ${ }^{41}$. El Capítulo I, artículos 117 a 122 TCEE ${ }^{42}$, bajo la rúbrica de disposiciones sociales, abordaba la cuestión relativa a la armonización de los sistemas sociales ${ }^{43}$. El artículo 117 TCEE abogaba nuevamente por la equiparación de las condiciones de vida y trabajo de los trabajadores a través de la aproximación de las disposiciones legales, reglamentarias y administrativas ${ }^{44}$. Sin embargo, como puede apreciarse, el artículo 117 TCEE no establecía ningún tipo de mecanismo, ni ningún tipo de obligación y/o competencia para los Estados miembros ni para los órganos de la Comunidad 45 , y se quedaba en un aséptico: Los Estados miembros convienen en la necesidad de promover la mejora de las condiciones de vida y de trabajo de los trabajadores, a fin de conseguir su equiparación por la vía del progreso ${ }^{46}$. Frente a lo dispuesto en el artículo 49 TCEE, el artículo 117 TCEE parecía suavizar la contundencia y puesta en marcha de la reiterada aproximación de las legislaciones nacionales en materia social, condicionado por la idea de que esta armonización de los sistemas sociales se produciría de manera natural como consecuencia del funcionamiento del mercado común ${ }^{47}$. Así, su párrafo segundo establecía que dicha evolución resultará tanto del funcionamiento del mercado común, que favorecerá la armonización de los sistemas sociales, como de los procedimientos previstos en el presente tratado y de la aproximación de las disposiciones legales, reglamentarias y administrativas ${ }^{48}$.

En el artículo 118 TCEE, se delegaba en la Comisión la tarea de promover una colaboración entre los Estados miembros en materia social y se enumeraban una serie de cuestiones entendidas como prioritarias: el empleo, el derecho del trabajo y las condiciones de trabajo, la formación y el perfeccionamiento profesionales, la Seguridad Social, la protección contra los accidentes de trabajo y las enfermedades profesionales, la higiene en el trabajo, el derecho de sindicación y las negociaciones colectivas entre empresarios y trabajadores. No obstante, tan generosa cantidad de ámbitos de actuación para el encuentro entre los Estados miembro se antojaba tarea complicada para poder obtener resultados concretos, más, si cabe, a través de los mecanismos que establecía el propio artículo $118 \mathrm{TCEE}^{49}$.

Frente a la laxitud del artículo 118 TCEE, el artículo 119 obligaba a los Estados miembros a garantizar la igualdad de retribución entre los trabajadores masculinos y femeninos para un mismo trabajo. Esta obligación se plasmaba en dos aspectos concretos. Por un lado, que la retribución establecida para un mismo trabajo remunerado por unidad de obra realizada fuese fijada sobre una misma unidad de medida y, por otro, que la retribución establecida para un trabajo remunerado por unidad de tiempo fuese la misma para un mismo puesto de trabajo. Tal vez acostumbrados a la tibieza social del Tratado, y siendo conscientes de las diferencias existentes en materia retributiva entre ellos, los Estados no vieron con buenos ojos la aplicación obligatoria del contenido de este precepto, forzando varias prórrogas en su aplicación con respecto a los plazos que establecía el propio artículo 119 TCEE50.

Por su parte, el artículo 120 TCEE abordaba una cuestión de carácter social que ya aparecía reflejada en el Informe Spaak ${ }^{51}$, como era la relativa a las vacaciones retribuidas. A este respecto, establecía que los Estados miembros procurarán mantener la equivalencia existente entre los regímenes de vacaciones retribuidas. El nivel de exigencia en esta materia, una vez más, resultaba 
muy poco ambicioso y la expresión procurarán mantener tan sólo pretendía garantizar el nivel de equiparación que ya existía entre los Estados en esta cuestión.

Finalmente, los artículos 121 y 122 TCEE cerraban el Capítulo 1, de Política Social, por un lado, facultando al Consejo para atribuir a la Comisión funciones para la aplicación de medidas comunes, en particular, las relativas a la seguridad social de los trabajadores migrantes y, por otro lado, encomendando a la Comisión la tarea de incluir en su informe anual un capítulo especial sobre la situación social de la Comunidad.

El Capítulo 2 de este Título III estaba formado por seis artículos que, bajo la rúbrica de El Fondo Social Europeo 52 , recogían la idea de un fondo de reconversión ya planteado en el Informe Spaak, pero con carácter general, para todos los sectores productivos y mucho más ambicioso ${ }^{53}$. Si hasta el momento el TCEE había recogido, con mayor o menor profundidad, medidas ya tratadas con anterioridad, el Fondo Social Europeo constituía el primer instrumento creado ad hoc, regulado de manera completa, por el Tratado de la Comunidad Económica Europea ${ }^{54}$. El artículo 123 TCEE concebía el Fondo Social Europeo como una herramienta para mejorar las posibilidades de los trabajadores en el mercado común y contribuir así a la elevación de su nivel de vida y, aunque el propio artículo 123 TCEE parecía limitar sus funciones a fomentar, dentro de la Comunidad, las oportunidades de empleo y la movilidad geográfica y profesional de los trabajadores, en la práctica estas serían muchas más 55 .

Otro aspecto social fundamental en la puesta en marcha del Fondo Social Europeo, recogido en el artículo 124 TCEE, fue la participación de los agentes sociales en su administración, si bien de manera indirecta como miembros de un Comité de apoyo a la Comisión, que era a quien realmente encomendaba el Tratado la administración del mismo ${ }^{56}$.

El artículo 125 TCEE, de mayor contenido social, regulaba las aportaciones del Fondo Social Europeo $^{57}$, a los Estados miembros que lo solicitasen ${ }^{58}$, para garantizar a los trabajadores un nuevo empleo a través de su reconversión profesional o mediante el pago de indemnizaciones por traslado(artículo 125.1.a del TCEE), y a conceder ayudas a los trabajadores cuyo empleo fuese reducido o interrumpido temporalmente, total o parcialmente, a consecuencia de la reconversión de la empresa a otras actividades, de manera que se le garantizaba así el mismo nivel de retribución hasta que se recuperase la ocupación plena (artículo. 125.1.b del TCEE).El Fondo Social Europeo nació así como el instrumento encargado de engrasar el mercado común y la libre circulación de trabajadores ${ }^{59}$, facilitando financiación para la reconversión de trabajadores y empresas a las nuevas necesidades de un mercado en constante y rápida evolución y a una alta movilidad de mano de obra ${ }^{60}$. Con todo, debe advertirse que el Fondo Social Europeo no nació como instrumento para completar lagunas en la acción protectora de los sistemas nacionales ${ }^{61}$. Su finalidad era mucho más amplia y estaba orientada directamente a la formación y readaptación profesional, la movilidad geográfica de la mano de obra o la incorporación a las actividades de trabajo de grupos con especiales problemas de empleo 62 .

El apartado 2 del artículo 125 establecía una serie de requisitos que debían cumplir los trabajadores objeto de reconversión profesional con cargo a la contribución del Fondo Social Europeo $^{63}$. Esta contribución quedaba condicionada a que los trabajadores beneficiados por el Fondo, en paro forzoso, sólo hubieran podido ser empleados en una nueva profesión en la que, además, tendrían que haber estado un mínimo de seis meses de ocupación. De esta manera, el Fondo Social Europeo se garantizaba un uso correcto del mismo por parte de trabajadores efectivamente reconvertidos laboralmente. 
Por su parte, en lo relativo a las indemnizaciones por traslado, la aportación del Fondo Social Europeo quedaba condicionada a que los trabajadores, también en paro forzoso, se hubiesen visto obligados a un cambio de domicilio dentro de la Comunidad para ocupar un nuevo empleo, al menos, seis meses.

Para el caso de reconversión empresarial, el artículo 125 TCEE exigía a la empresa, para poder acceder a contribuciones a favor de sus trabajadores, que estos tuviesen nuevamente una ocupación plena en la empresa de, al menos, seis meses, que el Gobierno hubiese presentado el proyecto de reconversión elaborado por la empresa a la Comisión y que esta última lo hubiese aprobado.

Conscientes de la evolución constante de un mercado común recién creado, pero rápidamente cambiante, el artículo 126 TCEE recogía la facultad del Consejo de, una vez terminado el período transitorio, dejar de conceder, total o parcialmente sus contribuciones, o determinar nuevas funciones que pudieran ser atribuidas al mismo ${ }^{64}$. A su vez, el artículo 127 TCEE facultaba al Consejo para la adopción de las disposiciones reglamentarias necesarias para el funcionamiento del propio Fondo Social Europeo y los requisitos y condiciones en las que deberían hacerse sus contribuciones. Haciendo uso de esta facultad, en agosto de 1960 se publicó el Reglamento (CEE) no 9, relativo al Fondo Social Europeo ${ }^{65}$. En su considerando primero se establecía como misión del Fondo Social Europeo la de una contribución esencial para mejorar el nivel de vida de los trabajadores mejorando sus oportunidades de empleo y su movilidad geográfica y profesional. Para esto, el Reglamento (CEE) no 9 desarrollaba los requisitos y operativa de los supuestos de intervención del Fondo previstos en el artículo 125 TCEE. Además, aportaba una definición precisa del término trabajador desempleado a los efectos de actuación del Fondo66, incluyendo bajo este término a cualquier persona, al menos de dieciséis años de edad, registrada en una oficina de empleo como solicitante de empleo y privada de todo empleo asalariado o independiente, puntualizando que, en el caso de desempleados menores de 18 años, debía acreditarse una inscripción mínima de tres meses consecutivos ${ }^{67}$.

Siguiendo la redacción del artículo 2, a efectos de actuación del Fondo, tenía también la consideración de trabajador desempleado cualquier trabajador asalariado o trabajador por cuenta propia en una situación de subempleo ${ }^{68}$ manifiestamente prolongada ${ }^{69}$, registrado en un servicio público de empleo como demandante de un trabajo a tiempo completo, y aquellos otros trabajadores afectados por una reconversión, [...] siempre que dicha reconversión requiera correlativamente su formación profesional.

Finalmente, el TCEE quiso reservar un artículo dentro del capítulo dedicado a la regulación del Fondo Social Europeo para hacer una apuesta clara por la formación profesional frente a otras alternativas amparadas por el mismo ${ }^{70}$. En esta línea, el artículo 128 TCEE abogada por una política común de formación profesional, capaz de contribuir al desarrollo armonioso de las economías nacionales y del mercado común.

Si bien todo el contenido social del Tratado de Roma analizado hasta el momento, en mayor o menor medida, no contemplaba aspectos novedosos, sino que más bien se trataba de la materialización de propuestas ya planteadas (Informe Spaak) o de ampliación medidas ya contempladas en otros Tratados (CECA), en los artículos 193 a 198 TCEE se contemplaba la creación de un órgano genuino y no planteado hasta el momento, el Comité Económico y Social. Según la definición que contenía el artículo 193 TCEE, se trataba de un órgano de carácter consultivo compuesto por representantes de diferentes sectores de la vida económica y social ${ }^{71}$. 
Los artículos 194, 195 y 196 del TCEE regulaban la composición de miembros del Comité, así como los mecanismos para su elección, asignación de cargos, reglamento interno, etc.

El artículo 197 TCEE establecía, de manera genérica, la creación de secciones especializadas en las principales materias previstas en el Tratado, al tiempo que proponía expresamente la creación de dos secciones concretas, la sección de transportes y la sección de agricultura. Finalmente, el artículo 198 TCEE regulaba la función del Comité Económico y Social como órgano consultivo de carácter preceptivo, aunque no vinculante, en determinadas cuestiones previstas en el propio Tratado y en todos aquellos casos en los que consideren oportuno.

Como conclusión, el único aspecto novedoso del TCEE fue la creación de un órgano consultivo de carácter económico y social pero cuyas resoluciones, al no ser vinculantes, apenas podían tener transcendencia directa, real o concreta en materia social. Una vez más, la política social era más bien escasa ${ }^{72}$.

Ni siquiera la firma de la Carta Social Europea73, heredera del Convenio Europeo de Derechos Humanos $^{74}$, sirvió para dotar de un mayor contenido social, siquiera testimonial ${ }^{75}$, a los Tratados de la época debido a la falta de consenso entre los Estados sobre los derechos que se debían garantizar y su alcance ${ }^{76}$. En ella, especialmente en su parte segunda, se incluían una serie de derechos sociales tales como el derecho al trabajo y a una regulación equitativa del trabajo, derechos sindicales, la protección de la familia o la seguridad y la asistencia social77. En relación con el tema que nos ocupa, el artículo 12 de la Carta regulaba el ejercicio efectivo al derecho a la Seguridad Social mediante la adopción de medidas que garantizasen la igualdad de trato entre los nacionales de cada una de las partes contratantes y los de las demás partes en lo relativo a los derechos de Seguridad Social, incluida la conservación de las ventajas concedidas por las leyes de Seguridad Social, sean cuales fueren los desplazamientos que las personas protegidas pudieren efectuar entre los territorios de las partes contratantes ${ }^{78}$, o la concesión, mantenimiento y restablecimiento de los derechos de Seguridad Social, por medios tales como la acumulación de los períodos de seguro o de empleo completados de conformidad con la legislación de cada una de las partes contratantes ${ }^{79}$.

En conclusión, como ha podido observarse, la cuestión social en general, y del desempleo en particular, han estado al margen en todos los antecedentes al TCEE ${ }^{80}$. Este, que a pesar de tener un marcado carácter económico ${ }^{81}$, mostraba cierto avance en cuanto a su contenido social, ha pasado de puntillas por la cuestión del desempleo ${ }^{82}$. El aspecto de mayor carga social desarrollado por el Tratado de Roma fue la creación del Fondo Social Europeo que, si bien ha quedado claro que no fue concebido como una herramienta para completar lagunas en los sistemas de protección social nacionales ${ }^{83}$, desarrollaba ciertas funciones que, desde otra perspectiva, podrían entenderse como medidas para evitar o paliar situaciones de desempleo. No debe olvidarse que el FSE se concebía como un instrumento de formación y recualificación profesional que, unido a sus medidas indemnizatorias por traslado, evitaban, acortaban o mejoraban las situaciones de desempleo de los trabajadores afectados por procesos de reconversión empresarial. Por tanto, aunque de manera indirecta, el Fondo Social Europeo ponía su grano de arena en mitigar determinadas situaciones de desempleo. 


\section{EMPLEO Y DESEMPLEO EN EL DERECHO ORIGINARIO: DE ROMA A LISBOA}

La firma del Acta Única Europea84, en 1986, supuso un paso más en el avance del contenido social en el panorama europeo, aunque con matices en cuanto a su trascendencia ${ }^{85}$. Con distintos puntos de vista respecto a determinadas cuestiones, antes y después de la firma, los distintos países fueron ratificándola ${ }^{86}$. En una sub sección III, dedicada a la Política Social y de tan sólo 2 artículos $^{87}$, se introdujeron los artículos 118A y 118B en el TCEE. El nuevo artículo 118A TCEE encomendaba a los Estados miembros la promoción de medidas que mejorasen el medio de trabajo ${ }^{88}$, la seguridad y la salud de los trabajadores, al tiempo que fijaba como objetivo la armonización de dichas condiciones ${ }^{89}$. Para la consecución de estos objetivos, el nuevo artículo 118A facultaba al Consejo para la adopción ${ }^{90}$, por mayoría cualificada ${ }^{91}$, de directivas en las que deberían establecerse las disposiciones mínimas ${ }^{92}$, pero siempre teniendo en cuenta las condiciones y regulaciones técnicas existentes encada uno de los Estados miembros ${ }^{93}$. Sobre este particular, el propio apartado 3 del nuevo artículo 118A recordaba la potestad de los Estados miembros para el mantenimiento o la adopción de medidas de protección de las condiciones de trabajo acordes con las disposiciones del propio artículo 118A. Por su parte, el nuevo artículo 118B del TCEE pretendía favorecer la negociación colectiva a nivel europeo al encomendar a la Comisión, de una manera muy tibia ${ }^{94}$, el desarrollo del diálogo entre las partes sociales a escala europea, que podrá dar lugar, si estas últimas los consideran deseable, al establecimiento de relaciones basadas en un acuerdo entre estas $^{95}$. En resumen, la principal aportación de contenido social del AUE fue, por un lado, la posibilidad de legislar por mayoría cualificada en materias que hasta el momento requerían de la unanimidad y, por otro, animando a la Comisión a promover el diálogo social europeo ${ }^{96}$.

Por su parte, la aprobación en el año 1989 de la Carta Comunitaria de los Derechos Sociales Fundamentales de los Trabajadores tampoco aportó contenido efectivo alguno al panorama social europeo ${ }^{97}$. Las críticas que suscitó su aprobación, únicamente por once de los doce Estados miembros, unido a la ausencia de carácter vinculante ${ }^{98}$, dio lugar a que su contenido social quedase limitado a ser fuente de inspiración y orientación de los órganos comunitarios ${ }^{99}$ en sus actuaciones en materia social ${ }^{100}$.

\subsection{El punto de inflexión: el Tratado de Maastricht}

No fue hasta la firma del Tratado de la Unión Europea en Maastricht ${ }^{101}$ el momento en que la cuestión social tuvo presencia de manera sustancial en un Tratado ${ }^{102}$.No obstante, no se optó por incluirla en el propio articulado ${ }^{103}$. El contenido social del Tratado de Maastricht fue incluido en un Protocolo XIV ${ }^{104}$ y su correspondiente Acuerdo sobre la Política Social, anexo a él, que contenía la mayor apuesta en materia social hecha hasta el momento ${ }^{105}$.

El artículo 1 del Acuerdo definía como objetivos de la Comunidad, entre otros, el de una protección social adecuada, el desarrollo de los recursos humanos para conseguir un nivel de empleo elevado y duradero y la lucha contra las exclusiones, objetivos que, sin duda, indicaban una clara apuesta por la prevención y protección frente al desempleo. Tal y como se establecía en el artículo 2.1 del Tratado, el papel de la Comunidad en la consecución de estos objetivos sería de apoyo y complemento de la acción de los Estados miembros en estas cuestiones, es decir, nunca de sustitución sino como un complemento a las acciones estatales. 
El apartado 2 del artículo 2 facultaba al Consejo para la adopción, mediante directivas, de las disposiciones mínimas para la consecución de estos objetivos por mayoría cualificada ${ }^{106}$. La introducción expresa del mecanismo de mayoría cualificada para la adopción de acuerdos sobre estas materias no resultaba cuestión baladí, ya que ampliaba y agilizaba la intervención comunitaria en materia social ${ }^{107}$. Así, el artículo 2 del Acuerdo permitía la adopción de acciones, por mayoría cualificada, en cuestiones como la mejora del entorno de trabajo en relación con la seguridad y salud de los trabajadores, las condiciones de trabajo ${ }^{108}$, la información y consulta a los trabajadores, la igualdad de oportunidades en el mercado laboral, la igualdad de trato entre hombres y mujeres y la integración de las personas excluidas del mercado laboral ${ }^{109}$. Sin embargo, el apartado 3 del mismo artículo mantenía bajo el mecanismo de la unanimidad del Consejo cuestiones como la protección de los trabajadores en caso de rescisión del contrato laboral, la representación y defensa colectiva de los intereses de trabajadores y empresarios, las condiciones de empleo de los nacionales de terceros países, el régimen de contribuciones financieras para el fomento y la creación de empleo y la Seguridad Social y protección social de los trabajadores. Además, el apartado 6 del Acuerdo excluía expresamente de la competencia comunitaria las medidas sobre remuneraciones y sobre los derechos de sindicación, huelga y cierre patronal 110 . Resulta contradictorio que, al tiempo que se ampliaba la competencia social comunitaria, atendiendo al procedimiento para la adopción de acuerdos, se complicaba la consecución de medidas sobre esta materia por la dificultad de puntos de encuentro unánimes entre los Estados miembros en determinadas cuestiones ${ }^{111}$.

Por tanto, el Tratado de Maastricht amplió la competencia comunitaria en materia social, mejorando considerablemente el abanico de acciones susceptibles de ser adoptadas por la vía de la mayoría cualificada, si bien seguía requiriendo de la unanimidad del Consejo en cuestiones determinantes de índole social, lo que provocaba cierto efecto de frenada en esta materia ${ }^{112}$.

Tras la entrada en vigor del Tratado de Maastricht, la preocupación por la precaria situación del empleo en Europa tuvo una presencia creciente en cada una de las cumbres celebradas ${ }^{113}$. Esta preocupación quedó reflejada, desde pronto, en el Libro Blanco sobre el Crecimiento, Competitividad y Empleo: Retos y Pistas para entrar en el siglo XXI114, que sentó las bases de la política de empleo de la Unión Europea ${ }^{115}$. Comenzando por poner de manifiesto la alarmante situación del desempleo en Europa ${ }^{116}$, su apartado III, Empleo, contenía tres capítulos dedicados a la adaptación de los sistemas de educación y de formación profesional, a la conversión del crecimiento en empleo y a las exacciones obligatorias aplicables al trabajo. Fue, concretamente, en su capítulo 8, dedicado a convertir el crecimiento en empleo, donde más claramente se puso de manifiesto la idea de que el mercado, por sí solo, no podía resolver los problemas del desempleo ${ }^{117}$. Del mismo modo, todos los Estados miembros coincidían en señalar causas de índole estructural y el mal funcionamiento del mercado de trabajo como culpables de los graves problemas de desempleo que padecían, estableciendo como prioridad la lucha contra el desempleo de los jóvenes y de larga duración, y contra la exclusión social ${ }^{118}$. El Libro Blanco aportó un análisis del nivel de desempleo registrado y encubierto, la baja tasa de empleo, las divergencias en la creación de empleo en la Comunidad con respecto a otras economías, las dificultades que afectaban a grupos específicos ${ }^{119}$, así como los costes económicos y sociales del desempleo ${ }^{120}$ y sus causas ${ }^{121}$.

Como propuesta de acción general, el Libro Blanco consideró imprescindible la adopción de medidas para reformar el mercado de trabajo. Esta medida general debía ir acompañada de otras específicas $^{122}$ encaminadas no solo a reducir el nivel de desempleo, sino más bien a desarrollar el 
empleo ${ }^{123}$, ampliando el entorno del empleo y aumentando la inversión comunitaria en recursos humanos $^{124}$. Con estos mimbres, en el Consejo Europeo de Essen del año 1994 vio la luz la Estrategia de Crecimiento y Empleo ${ }^{125}$, que dio un mayor papel a la Comisión y al Consejo en la supervisión de las políticas nacionales en materia de empleo ${ }^{126}$. Posteriormente, en los Consejos Europeos de Turín, Florencia y Dublín, celebrados a lo largo del año 1996, se sentaron las bases para una política común en materia de empleo, al tiempo que se iniciaban los trabajos previos para la inclusión, vía modificación, de un apartado específico sobre esta materia en el Tratado.

\subsection{La necesaria presencia del desempleo en el cuerpo de los Tratados}

Con la firma del Tratado de Ámsterdam, el 2 de octubre de 1997127, la preocupación por el empleo en Europa quedó plasmada de manera formal por vez primera en el Derecho originario ${ }^{128}$. Por un lado, se incluyó dentro del articulado del Tratado el contenido del Acuerdo de Política Social del Tratado de Maastricht ${ }^{129}$, lo que frenó un desigual desarrollo social entre los Estados ${ }^{130}$, dio mayor peso jurídico ${ }^{131}$ y pacificó la controversia interpretativa sobre los efectos jurídicos que había generado, pasando a ser su contenido, plenamente, derecho originario ${ }^{132}$.

Por otro, se creó dentro del Tratado un apartado específico en materia de empleo, dando un paso más hacia la convergencia de las políticas nacionales en este aspecto ${ }^{133}$. Ambos aspectos daban fe de la preocupación que la situación del empleo generaba en el momento ${ }^{134}$, lo que llevó a algún autor a señalar que se trataba del principal giro social en todo el proceso de construcción comunitaria actual135.

Muestra de esta preocupación por el empleo era su transversal presencia a lo largo de todo el cuerpo del Tratado, comenzando por el artículo 1, que fijó como un objetivo de la Unión un alto nivel de empleo. El artículo 2.19 TA creó un nuevo Título VI bis que, bajo el epígrafe Empleo ${ }^{136}$, introdujo seis nuevos artículos a través de los cuales la cuestión del empleo entró plena y formalmente en el Tratado ${ }^{137}$.

El artículo 109N TCE abogaba por la coordinación de las políticas nacionales en materia de empleo al establecer la necesidad de una estrategia coordinada para el empleo, en particular, para potenciar una mano de obra cualificada, formada y adaptable y mercados laborales con capacidad de respuesta al cambio económico ${ }^{138}$. El artículo 1090 TCE hacía una llamada de atención a los Estados para la consecución de los objetivos del Tratado en materia de empleo, al tiempo que se les emplazaba a contemplar el empleo como un asunto de interés común y a coordinar sus actuaciones sobre este ámbito en el seno del Consejo. Por su parte, el artículo 109P TCE, dentro del respeto a las competencias nacionales, encomendaba a la Comunidad el fomento de la cooperación entre los Estados en materia de empleo, a fin de conseguir un alto nivel de empleo ${ }^{139}$. El apartado 2 de este artículo 109P TCE volvía a insistir en la necesidad de que la formulación de políticas y medidas comunitarias debería tenerse en cuenta el objetivo de un alto nivel de empleo ${ }^{140 .}$

Por su parte, en el artículo 109Q TCE, se establecían los procedimientos o vías de comunicación, en relación a políticas de empleo, entre el Consejo, la Comisión y los Estados miembros. Por un lado, se encomendaba al Consejo la misión de examinar anualmente la situación del empleo en la Comunidad, basándose en un informe que debería elaborar con la Comisión. En el apartado 2 del 
artículo se establecía el procedimiento para la elaboración, por parte del Consejo, de orientaciones que los Estados miembros deberían tener en cuenta en sus respectivas políticas de empleo. Sobre éstas, en virtud del apartado 3 del artículo 109Q TCE, los Estados venían obligados a comunicar anualmente al Consejo y a la Comisión todas las medidas adoptadas en política de empleo. A la vista de esta información, el Consejo adquiría la facultad de formular recomendaciones.

El artículo 109R TCE volvía a poner el énfasis en la necesidad de cooperación entre los Estados miembros, poniendo en manos del Consejo la adopción de medidas que fomentasen esta cooperación entre Estados en el ámbito del empleo, facilitando, entre otras, análisis comparativos, asesoramiento, difusión de buenas prácticas, etc.

Finalmente, en el artículo 109S TCE, se creaba el Comité de Empleo, órgano de carácter consultivo con la finalidad, nuevamente, de fomentar la coordinación entre los Estados miembros en materia de políticas de empleo y del mercado laboral, en concreto, supervisando la situación del empleo y políticas de empleo de los Estados y emitiendo, previa solicitud o a iniciativa propia, dictámenes encaminados a una efectiva cooperación en materia de empleo.

Por su parte, los artículos 117 a 120 del TCE recogían el contenido del Acuerdo de Política Social anexo al Tratado de Maastricht, aunque con una salvedad. Mientras que en el Tratado de Maastricht regía el procedimiento de cooperación para la adopción de medidas relativas a la mejora del entorno de trabajo, las condiciones de trabajo, la integración de las personas excluidas del mercado de laboral, etc., el Tratado de Ámsterdam se posicionó a favor de un procedimiento de codecisión para la adopción de medidas en sobre estos aspectos ${ }^{141}$.

El Consejo Europeo de Niza de año 2000 trajo consigo dos nuevos instrumentos al Derecho de la Unión. Por un lado, la Carta de los Derechos Fundamentales de la Unión Europea ${ }^{142}$ y, por otro, el Tratado de Niza ${ }^{143}$. Atendiendo a su contenido en materia de empleo, la Carta contenía en su Capítulo IV un total de 12 artículos de marcado contenido social ${ }^{144}$. En particular, sobre la cuestión que nos ocupa, el artículo 30 garantizaba el derecho del trabajador a una protección en caso de despido injustificado, mientras que el artículo 34 reconocía el derecho al acceso de prestaciones de seguridad social y garantizaba esta protección en casos como, entre otros, situaciones de pérdida de empleo. Más que el valor jurídico de la Carta ${ }^{145}$, puesto en cuestión por varios Estados dado su particular carácter ${ }^{146}$, su importancia radicaba en que se ponían al mismo nivel de protección los derechos sociales y otros derechos incuestionables como el derecho a la vida, a la salud, a la libertad, etc ${ }^{147}$.

Por su parte, el Tratado de Niza del año 2001 apenas supuso avance alguno en cuanto a contenido social148, recogiendo todo lo establecido en su antecesor e introduciendo como novedades en su artículo 137 dos nuevos ámbitos de actuación en materia social por parte de la Comunidad: la lucha contra la exclusión social (art. 137.j) y la modernización de los sistemas de protección social (art. 137.k) ${ }^{149}$. Además, el apartado 2 del artículo 137 introdujo la posibilidad de que el Consejo pudiera aplicar el procedimiento de codecisión a materias sometidas, con carácter general y hasta el momento, al régimen de la unanimidad ${ }^{150}$. No obstante, esta posibilidad no se contempló para el ámbito de la Seguridad Social y la protección social de los trabajadores, para los que la unanimidad se mantuvo como procedimiento obligatorio ${ }^{151 .}$

La disparidad de criterios existentes entre los Estados miembros acerca de la eficacia jurídica de la Carta de los Derechos Fundamentales de la Unión Europea152, el fallido intento de Constitución Europea del año $2004^{153}$ y la necesidad de reorganizar, simplificar y/o clarificar 
determinados aspectos de los tratados anteriores dieron lugar en diciembre de 2007 al nacimiento del Tratado de Lisboa ${ }^{154}$ que, ya de entrada, cambiaba la denominación del anterior ${ }^{155}$, pasando a ser el nuevo Tratado de Funcionamiento de la Unión Europea.

Atendiendo al contenido social del TFUE ${ }^{156}$, amén de numerosas referencias en aras de la consecución de un mayor nivel de empleo, cambios en la denominación y localización dentro del TFUE de los títulos IX (Empleo) y X (Política Social) ${ }^{157}$ y el intento de aclaración de competencias ${ }^{158}$, en relación con la cuestión del desempleo, el nuevo Tratado no incluía de manera directa aportación novedosa sobre la materia ${ }^{159}$, aunque podría decirse que sí lo hacía de manera indirecta.

En primer lugar, el artículo 2.3 TFUE establecía que los Estados miembros coordinarán sus políticas económicas y de empleo [...] para cuya definición la Unión dispondrá de competencia, dando continuidad a lo ya dispuesto en el Tratado de Ámsterdam y manteniendo la preocupación sobre el empleo ${ }^{160}$. El artículo 5, el TFUE precisó un poco más y diferenció entre políticas de empleo y políticas sociales ${ }^{161}$, dando una mayor intensidad a las primeras frente a las segundas ${ }^{162}$. Así, en el apartado 2 del artículo 5 se estableció que la Unión tomará medidas para garantizar la coordinación de las políticas de empleo de los Estados miembros, posibilitando una clara iniciativa de acción en esta materia. Sin embargo, el apartado 3 del artículo 5 disponía que la Unión podrá tomar iniciativas para garantizar la coordinación de las políticas sociales de los Estados miembros, dejando completamente abierta la posibilidad de hacerlo o no. Obsérvese, por tanto, la diferencia en la intensidad entre tomar medidas y/o poder tomar iniciativas.

El TFUE incorporó también en su articulado, artículo 6, las disposiciones de la Carta de los Derechos Fundamentales de la Unión Europea asumiendo, por tanto, las garantías de protección ante despido injustificado, protección en casos de pérdida de empleo, etc, recogidas en la misma ${ }^{163}$. De esta manera otorgó total validez y efectos jurídicos a la, en su momento, denostada Carta al incorporarla directamente al Derecho originario ${ }^{164}$.

Por si la competencia de los Estados no había quedado suficientemente remarcada, el artículo 48 del TFUE introducía una nueva vía de revisión en favor de los Estados sobre proyectos de actos administrativos que, a juicio de estos, pudieran poner en peligro sus sistemas de Seguridad Social. En virtud de este mecanismo, un Estado podría remitir al Consejo Europeo cualquier acto legislativo en materia de Seguridad Social que, previsiblemente, pudiera alterar su ámbito de aplicación, su coste, su estructura financiera o su equilibrio financiero ${ }^{165}$.

En relación con el procedimiento de adopción de acuerdos por parte del Consejo, el nuevo Tratado mantuvo también la exigencia de la unanimidad para los ámbitos de Seguridad Social y protección social de los trabajadores ${ }^{166}$.

\section{CONCLUSIONES}

Como se ha puesto de manifiesto, la política social no ha sido objeto de interés preferente en los Tratados $\mathrm{y}$, por lo general, su presencia ha estado siempre supeditada a las cuestiones económicas ${ }^{167}$ y políticas, unas veces como medio, otras como consecuencia ${ }^{168}$.

La presencia de la cuestión del desempleo en los Tratados ha sido, por lo general, de mero contenido declarativo ${ }^{169}$. Habida cuenta de la finalidad claramente económica de las primeras 
etapas, lo social tuvo siempre una presencia testimonial y, en todo caso, supeditada a la prioridad económica. El desarrollo de lo social devendría de manera natural del desarrollo económico. Por lo tanto, lo prioritario fue actuar sobre lo económico.

Tan solo el preocupante nivel de desempleo en Europa a finales de los años ochenta y principios de los noventa hizo reaccionar a los Estados ante la evidencia de que las acciones centradas únicamente sobre los aspectos económicos no aportaban los resultados esperados sobre el desarrollo social, y sobre el empleo en particular, por lo que la cuestión social comenzó a ganar presencia, si bien su desarrollo fue ciertamente controvertido.

La limitación competencial de la Unión en esta materia, unido a las recelosas políticas estatales, provocaron un desarrollo lento y desigual de la cuestión social. Así, mientras que las cuestiones relativas a la libre circulación de trabajadores han experimentado un importante y cohesionado desarrollo, los aspectos de Seguridad Social y protección social han estado siempre anclados a la regla de la unanimidad.

Los avances que se han producido en materia social no han tenido, por lo general, una fácil entrada en el articulado de los Tratados, teniendo que optarse en un primer momento por vías alternativas. Así, por ejemplo, debe recordarse que el mayor paquete de contenido social del derecho originario tuvo que acomodarse en un primer momento en un Protocolo anexo al Tratado de Maastricht, pasando a estar plenamente incorporado años después por el Tratado de Ámsterdam. Del mismo modo, ha sido frecuente el uso de fórmulas de exclusión voluntaria ante disposiciones de carácter social, especialmente por parte del Reino Unido ${ }^{170}$. Finalmente, la progresiva erosión de la regla de la unanimidad y la extensión de la regla de la mayoría cualificada a un mayor número de ámbitos ha sido determinante para un mayor desarrollo de la cuestión social.

En consecuencia, la principal vía de desarrollo en materia de desempleo en el ámbito del Derecho de la Unión Europea ha sido a través de instrumentos de Derecho derivado. Los Tratados, de marcado carácter político y económico, salvo alguna honrosa y limitada excepción, dejaron prácticamente al margen la cuestión social en general y la cuestión del desempleo en particular. En el mejor de los casos, la cuestión social se entendió como una consecuencia, a un segundo nivel, de la cuestión económica. La idea de que una mejora de la economía traería consigo una mejora social, hizo que los esfuerzos normativos en el derecho originario se centrasen únicamente en la primera.

\section{Bibliografía}

Alcaide Fernández, J., Casado Raigón, R., Arcos Vargas, M., García García-Revill, M., Hinojo Rojas, M., Martín Martínez, M.M., Salinas de Frías, A. y Vázquez Gómez, E.M. (2014). Curso de Derecho de la Unión Europea. Madrid: Tecnos.

Alonso García, B. (2002). El empleo en la Unión Europea y las acciones del Fondo Social. Revista Española de Derecho del Trabajo, 114.

Anónimo. (1957). Politique sociale et Marché commun. Revista Droit Social, 12.

Aparicio Tovar, J. (2005). Introducción al Derecho Social de la Unión Europea. Albacete: Editorial Bomarzo.

Arrigo, G. (1998). Il diritto del lavoro dell'Unione europea. Tomo I. Milano: Giuffrè Editore. 
Ashiagbor, D. (2001). EMU and the Shift in the European Labour Law Agenda: From "Social Policy" to "Employment Policy". European Law Journal, Vol. 7, 3.

Ballester Pastor, M.A. (2009). Los derechos sociales en la Carta Comunitaria de derechos fundamentales y en el Tratado de Lisboa. Revista Actualidad Laboral, 15.

Bar Cendón, A. (2012). La política Social de la Unión Europea. Revista jurídica de los Derechos Sociales Lex Social, 2.

Bartolomei de la Cruz, H. (1989). La Carta Social Europea y la Organización Internacional del Trabajo: veinticinco años de colaboración ejemplar. En Lezertua, M. y Vida Soria, J. (Coords.). La Carta Social Europea en la perspectiva de la Europa del año 2000. Madrid: Centro de Publicaciones del Ministerio de Trabajo y Seguridad Social.

Beneyto, J.M. (1989). Europa 1992. El Acta Única Europea: mercado interior y cooperación política europea. Madrid: Editorial Civitas.

Bercusson, B. (2009). European Labour Law. Cambridge: Cambridge University Press.

Bercusson B. (2009). Maastricht: A fundamental change in European labour law. En Labour Law an Social Europe. Selected writings of Brian Bercusson. Brussels: European Trade Union Institute (ETUI).

Bercusson, B., Clauwaert, S. y Schömann, I. Legal prospects and legal effects of the EU Charter. En Bercusson, B. (Ed.). European Labour Law and the EU Charter of Fundamental Rights. Germany: Nomos.

Bilbao Ubillos, J. (2009). El Tratado de Lisboa y la regulación básica de la cuestión económica y social en la Unión Europea. En Matía Portilla, FJ. (Dir.). Estudios sobre el Tratado de Lisboa. Granada: Editorial Comares.

Blanpain, R. (2006). European Labour Law. Netherlands: Kluwer Law International.

Blanpain, R. (1999). European Labour Law. The Hague: Kluwer Law International.

Blázquez Agudo, E.M. (2006). El futuro de la libre circulación de trabajadores. Repensando su contenido a partir de la Directiva Marco sobre mercado interior. Revista del Ministerio de Trabajo y Asuntos Sociales, 62.

Bonet Marco, E. (1988). Introducción al Acta Única Europea. Madrid: ESIC Editorial, Colección Estudios, 13.

Cabeza Pereiro, J. (2000). La cuestión social en el Derecho originario de la Unión Europea. Revista Documentación Laboral, 63.

Colina Robledo, M., Ramírez Martínez, J.M. y Sala Franco, T. (1995). Derecho Social Comunitario. Valencia: Tirant lo Blanch.

Cruz Villalón, J. (2000). La dimensión social de la Unión Europea: surgimiento y evolución. En Cruz Villalón, J. y Pérez del Río, T. (Coords.). Una aproximación al Derecho Social Comunitario. Madrid: Editorial Tecnos.

Dans Álvarez de Sotomayor, L. (2011). La libre circulación de personas tras el Tratado de Lisboa. Revista del Ministerio de Trabajo e Inmigración, 92.

Dans Álvarez de Sotomayor, L. (2009). La progresiva ampliación del campo de aplicación personal en la normativa social comunitaria: extensión y límites del derecho de libre circulación. En AAVV, Los mercados laborales y las políticas sociales en Europa. XX Congreso Nacional de Derecho del Trabajo y de la Seguridad Social. Madrid: Ministerio de Trabajo e Inmigración.

De la Villa Gil, L.E. (2001). La Carta de los Derechos Fundamentales de la Unión Europea. Revista del Ministerio de Trabajo y Asuntos Sociales, 32. 
Domínguez Garrido, J.L. (1986). La problemática del Fondo Social Europeo. Revista Documentación Laboral, 19.

Domínguez Garrido, J.L. (1985). La reforma de 1983 del Fondo Social Europeo. Madrid: Ministerio de Trabajo y Seguridad Social, Informes y Documentos.

Fernández de Casadevante Romaní, C. (Coord.), Carrera Hernández, F.J., Ruiloba Alvariño, J., Garrido Rebolledo, V. (2015). Nociones Básicas de Derecho de la Unión Europea. Madrid: Editorial Universitaria Ramón Areces.

Fernández Docampo, B. (2006). La participación de los trabajadores en el Derecho Social Comunitario. Valencia: Tirant lo Blanch.

Fernández Márquez, O. (2016). Libre circulación de personas por el territorio comunitario. En García Murcia, J. (Dir.) Libertades de circulación y derechos de protección social en la Unión Europea. Lisboa: Editorial Juruá.

Fernández Navarrete, D. (2018). Historia de la Unión Europea. De los orígenes al Brexit. Madrid: UAM Ediciones.

Fernández Riquelme, S. (2009). Política Social en la Unión Europea: del Estado del Bienestar a la Europa social. La Razón Histórica. Revista Hispanoamericana de Historia de las Ideas, 9.

Fernández Rodríguez, C. (2003). El Fondo Social Europeo. Revista de Derecho de la Unión Europea, 5, 2º semestre.

Fraile, J.M. (1994). El Fondo Social Europeo. Cuadernos de Relaciones Laborales, 4. Madrid: Editorial Complutense.

Fundación Robert Schuman. (2001). Cuestiones sobre Europa, 204.

Galantino, L. (2001). Diritto Comunitario del Lavoro. Torino: G. Giappicheli Editore.

Galiana Moreno, J.M. (1998). Aspectos sociales del Tratado de Amsterdam. Revista Española de Derecho del Trabajo, 88.

Gárate Castro, J. (2010). Transformaciones en las normas sociales de la Unión Europea. Madrid: Editorial Universitaria Ramón Areces.

Gárate Castro, J. (1987). Apuntes sobre la regulación y funcionamiento del Fondo Social Europeo. Revista Española de Derecho del Trabajo, 30.

Gárate Castro, J. (1987). El Fondo Social Europeo: configuración actual. Revista Actualidad Laboral, 2.

García Murcia, J., Menéndez Sebastián, P. El Fondo Social Europeo. Revista Noticias de la Unión Europea, 234.

Giubboni, S. (2006). Social rights and market freedom in the European Constitution: A labour law perspective. New York: Cambridge University Press.

Gomis Vidal, P.L. (1999). La política social y de empleo en el Tratado de Amsterdam. Madrid: Consejo Económico y Social.

Gutiérrez Espada, C., Cervell Hortal, M.J., Piernas López, J.J., Garciandía Garmendia, R. (2012). La Unión Europea y su derecho. Madrid: Editorial Trotta.

Gutiérrez Espada, C. (1991). El sistema institucional de las Comunidades Europeas. Madrid: Editorial Tecnos.

Gutiérrez-Solar Calvo, B. (2000). El desplazamiento temporal de trabajadores en la Unión Europea. Navarra: Aranzadi Social. 
Herreros López, J.M. (2004). El contenido social de la Carta de los Derechos Fundamentales. Boletín Jurídico de la Universidad Europea de Madrid, 7.

Hierro Hierro, F.J. (2019). La protección social en la Unión Europea. En Cardenal Carro, M. y Pérez Campos, A.I. (Dirs.), Areta Martínez, M. (Coord.). Derecho del trabajo y protección social en la Unión Europea: situación actual y perspectivas de futuro. Madrid: Dykinson. Servicio de Publicaciones de la URJC.

Hierro Hierro, F.J. (2004). La contribución del Fondo Social Europeo al fomento de la igualdad de oportunidades entre mujeres y hombres. Tribuna Social: Revista de Seguridad Social y Laboral, 57.

Jimena Quesada, L. (2009). La Carta Social Europea y la Unión Europea. Revista Europea de Derechos Fundamentales, 13, 1ํㅗㄴ.

Joly, B. (2005). Politiques de l'emploi en Europe: les grandes tendances chez les voisins de la France. Revista Droit Social, 1.

Kerschen, N. y Omarjee, I. (2010). La stratégie européene pour l'emploi: un exemple de rencontre entre une politique européenne et le droit communautaire. Revista Droit Social, 2.

Kramer, D. (2017). From worker to self-entrepreneur: The transformation of homo economicus and the freedom of movement in the European Union. European Law Journal, Vol. 23, 3 - 4.

Lasa López, A. (2012). Los derechos sociales en el constitucionalismo de mercado: aporías de la dimensión social en la Unión Europea. Bilbao: Servicio Editorial de la Universidad del País Vasco.

Linde Paniagua, E. (2003). La libre circulación de los trabajadores versus libre circulación de las personas. La ciudadanía europea. Revista de Derecho de la Unión Europea, 5.

López-Romero González, P. (2003). La política de empleo en la Unión Europea. Revista Universitaria de Ciencias del Trabajo. Universidad de Valladolid, 3-4.

Maestro Buelga, G. (2006). El impacto de la ampliación de la UE sobre el modelo social europeo. Revista de Derecho Comunitario Europeo, 23.

Maldonado Gago, J. (1997). Política Social de la Unión Europea. Revista de Estudios Políticos Nueva Época, 95.

Mangas Martín, A. y Liñán Nogueras, D.J. (1996). Instituciones y Derecho de la Unión Europea. Madrid: Editorial Mc Graw Hill.

Marcuello Moreno, M.M. (2001). La política social de la Unión Europea. Revista Noticias de la Unión Europea, 195.

Márquez Prieto, A. (2001). La protección por desempleo en España y otros Estados europeos. Madrid: Ministerio de Trabajo y Asuntos Sociales. Subdirección General de Publicaciones.

Martín Valverde, A. (1986). El Fondo Social y la política de empleo en la Comunidad Europea. Bilbao: La Ley.

Martín Valverde, A. y Miranda Boto, JM. (2010). El Tratado de Lisboa y el Derecho Social de la Unión Europea. Revista Actualidad Laboral, 19.

Martínez Yáñez, N.M. (2020). La Carta de Derechos Fundamentales de la UE y los derechos profesionales de los trabajadores autónomos. Revista Temas Laborales, 151.

Martínez Yáñez, N.M. (2015). La coordinación de las políticas sociales y de empleo en el vórtice de la gobernanza económica europea. Revista de Derecho Comunitario Europeo, 52.

Martínez Yáñez, N.M. (2011). La coordinación de las políticas de empleo a la luz del Tratado de Lisboa. Revista del Ministerio de Trabajo e Inmigración, 92. 
Masala, P. y Valdés Dal-Re, F. (2019). The future of Social Europe and of European Integration at a Crossroads: How can we recover and enforce solidarity as a fundamental principle of European Constitutional Law (or die)?. European Papers, Vol. 4, 1.

Mengozzi, P. (1982). European Community Law: from common market to European Union. London: European Law Library. Wolters Kluwer Academic Publishers Group.

Miranda Boto, J.M. (2017). El derecho social de la Unión Europea en la encrucijada: entre la parálisis legislativa y el impulso judicial. Revista del Ministerio de Empleo y Seguridad Social, 127.

Miranda Boto, J.M. (2011). La competencia comunitaria en materia de Seguridad Social. Noticias de la Unión Europea, 319.

Miranda Boto, J.M. (2009). Mehr Papiere Und Beamten? La creciente importancia del Consejo Europeo en materia social. Revista Temas Laborales, 102.

Miranda Boto, J.M. (2008). La incidencia del Tratado de Lisboa en el ámbito social. Revista Temas Laborales, 97.

Miranda Boto, J.M. 82008). Antecedentes Sociales de los Tratados de Roma. Revista Dereito, Vol. 17, 1.

Miranda Boto, J.M. (2008). Los humildes orígenes de la política social comunitaria. Revista Dereito, Vol. 17, 2.

Miranda Boto, J.M. (2003). El principio de subsidiariedad en el ordenamiento comunitario y sus aplicaciones en materia social. Revista del Ministerio de Trabajo y Asuntos Sociales, 47.

Monereo Pérez, J.L. y Fernández Bernat, J.A. (2017). El pilar europeo de los derechos sociales: un mecanismo insuficiente para garantizar la dimensión social. La Ley Unión Europea, 49.

Monereo Pérez, J.L. (1992). Carta comunitaria de derechos sociales fundamentales de los trabajadores (I). Revista Española de Derecho del Trabajo, 56.

Monereo Pérez, J.L. (1993). Carta comunitaria de derechos sociales fundamentales de los trabajadores (II). Revista Española de Derecho del Trabajo, 57.

Montes Fernández, F.J. (2014). El Consejo de Europa. Anuario Jurídico y Económico Escurialense, XLVII.

Montoya Melgar, A., Galiana Moreno, J.M., Sempere Navarro, A.V. (1994). Derecho Social Europeo. Madrid: Tecnos.

Montoya Melgar, A., Galiana Moreno, J.M., Sempere Navarro, A.V. (1988). Instituciones de Derecho Social Europeo. Madrid: Tecnos.

Neal, A.C. (2004). Fundamental Social Rights in the European Union: "floor of rights" or "drift to the bottom? En Neal, A.C. (Ed.). The Changing Face of European Labour Law and Social Polic. La Haya: Kluwer Law International.

Nielsen, R. (2013). EU Labour Law. Copenhagen: DJOF Publishing.

Nogueira Guastavino, M. (2012). La progresiva política social de la Unión Europea. En Nogueira Guastavino, M., Fotinopoulou Basurko, O., Miranda Boto, J.M. (Dirs.). Lecciones de Derecho Social de la Unión Europea. Valencia: Tirant lo Blanch.

Oficina de Publicaciones Oficiales de las Comunidades Europeas. Libro Blanco sobre el Crecimiento, Competitividad y Empleo: Retos y Pistas para entrar en el siglo XXI. Luxemburgo. Suplemento 6/93

Ojeda Avilés, A. (2013). Derecho transnacional del trabajo. Valencia: Tirant lo Blanch.

Palomino Saurina, P. (2013). La política de empleo en la Unión Europea a través de los Consejos Europeos. Revista Relaciones Laborales, 4. 
Pedrosa Sanz, R. (2009). El desarrollo histórico de la Política Social de la Unión Europea y su estado actual. Estudios de Economía Aplicada, Vol. 27-3.

Peredo Linacero, J.A. (1994). Algunas consideraciones sobre la puesta en práctica del Acuerdo sobre la Política social del Tratado de Maastricht. Cuadernos de Trabajo Social, 7. Madrid: Editorial Universidad Complutense.

Pérez Bustamante, R. (1997). Historia de la Unión Europea. Madrid: Dykinson.

Pérez de los Cobos Orihuel, F. (1994). El derecho social comunitario en el Tratado de la Unión Europea. Madrid: Civitas.

Pérez del Río, T. (1991). La dimensión social del Mercado Único Europeo. Revista Española de Derecho del Trabajo, 47.

Pons Carmena, M. (2015). Modelo social europeo y protección de los derechos sociales fundamentales. Madrid:Editorial Reus.

Plender, R., Pérez Santos, J. (1985). Introducción al Derecho Comunitario Europeo. Madrid: Editorial Civitas.

Prieto Suárez, R. (2008). La Carta Social Europea y el Comité Europeo de Derecho Sociales (El sistema de informes y las reclamaciones colectivas). Revista Europea de Derechos Fundamentales, 11.

Raepenbusch, S.V. (2011). Droit Institutionnel de L’Union Européene. Bélgica: Larcier.

Ribas J.J., Jonczy M.J., Séché J.C. (1980). Derecho Social Europeo. Madrid: Ministerio de Trabajo. Instituto de Estudios Sociales.

Rodríguez-Piñero y Bravo-Ferrer, M. (1978). La Carta Social Europea y su puesta en práctica. Revista de Instituciones Europeas, 5.

Rodríguez-Piñero Royo, M.C., Castellano Burguillo, E. (2005). La armonización comunitaria y el modelo social europeo. Revista Documentación Laboral, 74.

Rodríguez-Piñero Royo, M.C., Castellano Burguillo, E. (2001). La política de empleo de la Unión Europea. Trabajo: Revista Andaluza de Relaciones Laborales, 10.

Rodríguez-Piñero Royo, M.C. (1998). Los aspectos sociales del Tratado de Ámsterdam. En Aragón Medina, J. (Coord.). Euro y Empleo. Madrid: Colección de Estudios. Consejo Económico y Social.

Rogowski, R. (2008). The European Social Model and the law and policy of transitional labour markets in the European Union. En The European Social Model and Transitional Labour Markets. England: Ashgate Publishing Limited.

Rojo Torrecilla, E. (2001). La Carta de Derechos Fundamentales de la Unión Europea y los derechos de información y consulta. Revista Temas Laborales, 59.

Ruiz de la Cuesta Fernández, S. (2004). Empleo y desempleo en la Unión Europea: del desinterés a la prioridad absoluta. En Desempleo. XIV Congreso Nacional de Derecho del Trabajo y de la Seguridad Social. Madrid: Ministerio de Trabajo y Asuntos Sociales.

Sala Franco, T., Ramírez Martínez, J.M. (1986). Introducción al Derecho social comunitario. Valencia: Tirant lo Blanch.

Salas Porras, M. (2019). Las libertades de circulación y establecimiento de trabajadores. Aportaciones para el avance de la dimensión social europea desde el enfoque transnacional. Navarra: Aranzadi.

Sánchez Fernández de Gata, D. (1995). Los caminos de la Unión Europea: los procesos de elaboración del Acta Única y del Tratado de Maastricht. Revista Noticias de la Unión Europea, 131. 
Sánchez-Rodas Navarro, C. (2018). Sobre la (in)competencia de las instituciones europeas para reformar los sistemas públicos de pensiones nacionales a la luz de la UE y de los Tratados Internacionales. Cuadernos de Derecho Transnacional, Vol. 1, 1.

Schmitt, M. (2010). La dimension sociale du traité de Lisbonne. Revista Droit Social, 6.

Sciarra, S. (1995). Social Values and the Multiple Sources of European Social Law. European Law Journal, Vol. 1, 1.

Sempere Navarro, AV., Pérez Campos, AI. (2000). El lugar de la política social comunitaria. Revista Noticias de la Unión Europea, 186.

Serrarens, P.J.S. (1954). La construction sociale de L'Europe. Revista Droit Social, 11.

Sevilla Merino, J., Ventura Franch, A. (2005). Evolución del Derecho social europeo. Revista del Ministerio de Trabajo y Asuntos Sociales, 57.

Sierra Nava, J.M. (1957). El Consejo de Europa. Madrid: Instituto de Estudios Políticos.

Swiatkowski, A.M. (2009). European Union citizenschip and the rights of access for welfare State: a comparison with welfare rights guaranteed by the Council of Europe as seen from the perspective of a new member State. En Neergaard, U., Nielsen, R., Roseberry, L.M. (Eds.). Integrating welfare functions into EU Law. From Rome to Lisbom. Copenhagen: DJOF Publishing.

Tessier, J. (1957). Le Conseil économique et social européen. Revista Droit Social, 11.

Thüsing, G. (2013). European Labour Law. Germany: C.H. Beck, Hart \& Nomos.

Torrents Margalef, J. (2000). La merecida normalización de la política social comunitaria. Revista Documentación Laboral, 61.

Tridimas, T. (2012). Competence after Lisbon: The exclusive search for bright lines. En Ashiagbor, D., Countouris, N., Lianos, I. (Ed.). The European Union after the Treaty of Lisbon. New York: Cambridge University Press.

Valticos, N. (1963). La Chartre Sociale Européene. Sa structure, son contenu, le contrôle de son application. Revista Droit Social, 8.

Vilariño Pintos, E. (1998). La construcción de la Unión Europea. Madrid: Arco/Libros, SL.

Vrillon, M.B. (1966). La libre circulation des travailleurs de la communauté économique européene dans l'optique du comité consultatif de la libre circulation. Revista Droit Social, 5.

Watson, P. (2009). EU Social and Employment Law. New York: Oxford University Press.

Zachert, U. (2002). Los derechos fundamentales de los trabajadores en la Carta Europea de Derechos Fundamentales. Revista Temas Laborales, 65.

NOTAS

\footnotetext{
${ }^{1}$ Este trabajo tiene su origen en la Tesis Doctoral “La protección por desempleo en el Derecho de la Unión Europea. Especial atención a la jurisprudencia del Tribunal de Justicia”, defendida por el autor el 30 de octubre de 2020 en la Universidad de Santiago de Compostela bajo la dirección del profesor José María Miranda Boto.

${ }^{2}$ Mangas Martín, A. y Liñán Nogueras, D.J. (1996). Instituciones y Derecho de la Unión Europea. Madrid: Editorial Mc Graw Hill. (p. 5).
} 
3 Gutiérrez Espada, C., Cervell Hortal, M.J., Piernas López, J.J. y Garciandía Garmendia, R. (2012). La Unión Europea y su derecho. Madrid: Editorial Trotta. (p. 17); Vilariño Pintos, E. (1998). La construcción de la Unión Europea. Madrid: Arco/Libros, SL. (pp. 11-12); Alcaide Fernández, J., Casado Raigón, R., Arcos Vargas, M., García García-Revill, M., Hinojo Rojas, M., Martín Martínez, MM., Salinas de Frías, A. y Vázquez Gómez, E.M. (2014). Curso de Derecho de la Unión Europea. Madrid: Tecnos. (pp. 33-34).

4 Iniciativa europea esencial para la recuperación económica. George C. Marshall, Universidad de Harvard, Junio de 1947.

${ }^{5}$ Mangas Martín, A. y Liñán Nogueras, D.J. (1996). Op. Cit. (pp. 7-8).

${ }^{6}$ Aparicio Tovar, J. (2005). Introducción al Derecho Social de la Unión Europea. Albacete: Editorial Bomarzo. (p. 23).

7 Gutiérrez Espada, C. (1991). El sistema institucional de las Comunidades Europeas. Madrid: Editorial Tecnos. (pp. 13-14).

${ }^{8}$ Sobre su nacimiento, objetivos y evolución, véase Van Raepenbusch, S. (2011). Droit Institutionnel de L'Union

Européene. Bélgica : Larcier. (pp. 18-22).

9 Vilariño Pintos, E. (1998).Op. Cit. (p. 19).

${ }_{10}$ Miranda Boto, J.M. (2008). Antecedentes Sociales de los Tratados de Roma. Revista Dereito, Vol. 17, 1. (pp. 123-136); Fernández de Casadevante Romani, C. (Coord.). Carrera Hernández, F.J., Ruiloba Alvariño, J. y Garrido Rebolledo, V. (2015). Nociones Básicas de Derecho de la Unión Europea. Madrid: Editorial Universitaria Ramón Areces. (pp. 35-36); Montes Fernández, F.J. (2014). El Consejo de Europa. Anuario Jurídico y Económico Escurialense, XLVII, (pp. 57-92). ${ }^{11}$ Resolución Económica y Social del Congreso de La Haya (7-10 de Mayo de 1948).

http://www.cvce.eu/en/obj/economic_and_social_resolution_of_the_hague_congress_7_10_may_1948-en-537c7689d702-4a15-88bd-4db51fd07b3a.html

${ }^{12}$ Si bien, a partir de recomendaciones de instituciones externas: "Les Hautes Partes contractantes se concerteront en vue d'appliqueur le plus tôt posible les recommandations d'ordre social, émanant d'institutions spécialisées, auxquelles Elles ont donné leur approbation, au sein de ces institutions, et qui présentent un intérêt pratique immédiat”. Serrarens, P.J.S. (1954). La construction sociale de L'Europe. Revista Droit Social, 11. (p. 672).

13 Como señala Montes Fernández "ante este Comité se presentaron dos proyectos totalmente opuestos, uno inglés y otro franco-belga. Inglaterra defendía la participación solo de los cinco países del Pacto de Bruselas y que el Consejo de Europa estuviese integrado por los representantes de los gobiernos. Por el contrario, Francia y Bélgica pugnaban por la creación de una Asamblea Europea, con miembros elegidos por los Parlamentos nacionales, que fuera el núcleo de un futuro Parlamento Europeo y cuya competencia estuviera por encima de los Estados miembros". Montes Fernández, F.J. (2014). Op. Cit. (p. 62).

${ }^{14}$ Para aproximar posiciones se propuso la creación de dos organismos: el Consejo de Europa y la Asamblea Consultiva Europea. El Reino Unido, por su parte, prestaron una contrapropuesta consistente en la creación de dos organismos: el Comité de Ministros y la Conferencia de Delegados. Ambas propuestas tuvieron que ir al Consejo Ejecutivo de los cinco reunidos en Londres el 26 de enero de 1945. Los británicos cedieron, de forma inopinada, y aceptaron la creación del Consejo de Europa integrado por un Comité de Ministros y una Asamblea Consultiva, independientes de los Gobiernos". Ibídem, p. 62.

${ }^{15}$ En mayor profundidad sobre el nacimiento y fines del Consejo de Europa, véase Sierra Nava, J.M. (1957). El Consejo de Europa. Madrid: Instituto de Estudios Políticos.

${ }^{16}$ En palabras de Prieto Suárez "la adopción de la Carta Social Europea por parte del Consejo de Europa se hizo como un complemento al Convenio Europeo de Derechos Humanos [... ]. Aunque inicialmente se había barajado la idea de un instrumento único, fue imposible por la falta de consenso entre los Estados sobre qué derechos se debían garantizar, su alcance y el mecanismo de control”. Prieto Suárez, R. (2008). La Carta Social Europea y el Comité Europeo de Derecho Sociales (El sistema de informes y las reclamaciones colectivas). Revista Europea de Derechos Fundamentales, 11. (p. 356).

17 La Carta puede concebirse como un estándar o nivel mínimo para la protección de los derechos sociales". Prieto Suárez, R. Ibídem. (p. 356).

${ }^{18}$ Sobre su “laboriosa gestación” y contenido social, Rodríguez-Piñero y Bravo-Ferrer, M. (1978). La Carta Social Europea y su puesta en práctica. Revista de Instituciones Europeas, 5. (pp. 53 - 69).

${ }^{19}$ En materia de Seguridad Social, la Carta es bastante escueta, pues por entonces ya se encontraba en elaboración un convenio específico de Seguridad Social [... ] que se aprobaría en 1964". Ibídem. (p. 67). 
${ }^{20}$ Como señala Bartolomei de la Cruz, el establecimiento de estos servicios de empleo gratuitos para todos los trabajadores buscaba "la supresión progresiva de las agencias retribuidas de colocación con fines lucrativos y la reglamentación de las demás agencias de colocación". Bartolomei de la Cruz, H. (1989). La Carta Social Europea y la Organización Internacional del Trabajo: veinticinco años de colaboración ejemplar. En Lezertua, M. y Vida Soria, J. (Coords.). La Carta Social Europea en la perspectiva de la Europa del año 2000. Madrid: Centro de Publicaciones del Ministerio de Trabajo y Seguridad Social. (p. 139).

${ }^{21}$ Fundación Robert Schuman (2001). Cuestiones sobre Europa, 204.

${ }^{22}$ En palabras de Bar Cendón "no se puede olvidar que nos encontramos ante una experiencia de integración muy limitada, sobre un campo muy pequeño -el mercado del carbón y del acero-; no había, pues, mucho espacio para una política social, en términos propios. Más bien al contrario, se trataba de salvaguardar la competencia de los Estados miembros en este tipo de materias". Bar Cendón, A. (2012). La política Social de la Unión Europea. Revista jurídica de los Derechos Sociales Lex Social, 2. (p. 33).

${ }^{23}$ Por el artículo 68 la Comunidad pretende asegurar determinados beneficios a los trabajadores que, de esta forma, compensan una situación de reducción de salarios". Gomis Vidal, P.L. (1999). La política social y de empleo en el Tratado de Amsterdam. Madrid: Consejo Económico y Social. (p. 40).

${ }^{24}$ Miranda Boto, J.M. (2008). Op. Cit. (p. 128).

25 Tal y como señalan Ribas, Jonczy y Séché "a pesar del relativamente alto número de trabajadores extranjeros empleados en las minas y en las industrias siderúrgicas, los convenios de seguridad social bilaterales y multilaterales que ligaban los seis Estados firmantes del Tratado de París, no regulaban todas las cuestiones o lo hacían de una manera imperfecta, y dejaban subsistentes divergencias importantes, que eran otros tantos obstáculos a la libre circulación de trabajadores". Ribas, J.J., Jonczy, M.J. y Séché, J.C. (1980). Derecho Social Europeo. Madrid: Instituto de Estudios Sociales. Ministerio de Trabajo. (p. 219).

${ }^{26}$ Idea contenida también en el artículo 46 TCECA que encomendaba, literalmente, a la Alta Autoridad "participar, a instancia de los Gobiernos interesados, en el estudio de las posibilidades de reempleo, en las industrias existentes o mediante la creación de actividades nuevas, de la mano de obra que hubiere quedado disponible debido a la evolución del mercado o a las transformaciones técnicas".

${ }^{27}$ En palabras de Miranda Boto, "se había alejado de los nebulosos objetivos generales, de más relumbrón ciertamente, pero de más difícil conclusión y había centrado la atención en un sector específico, consiguiendo realizaciones concretas. Los poderes eran limitados, pero intensivos [... ]". Miranda Boto, J.M. (2008). Op. Cit. (p. 129). ${ }^{28}$ Pérez Bustamante, R. (1997). Historia de la Unión Europea. Madrid: Dykinson. (p. 95).

${ }^{29}$ Giubboni, S. (2006). Social rights and market freedom in the European Constitution: A labour law perspective. New York: Cambridge University Press. (p. 30).

30 "A more efficient allocation of these factors would contribute to increased standards of living". Kramer, D. (2017). From worker to self-entrepreneur: The transformation of homo economicus and the freedom of movement in the European Union. European Law Journal, Vol. 23, 3-4. (p. 179).

${ }^{31} \mathrm{El}$ procedimiento por el que se establece este espacio único se aparta del uso establecido hasta la fecha para los tratados internacionales ya que, en este caso, se cede el ejercicio de competencias, de los Estados-parte, a las instituciones creadas en los propios tratados con la finalidad de que dicten normas que serán vinculantes para los Estados firmantes y que por tanto condicionarán su actuación". Sevilla Merino, J. y Ventura Franch, A. (2005). Evolución del Derecho social europeo. Revista del Ministerio de Trabajo y Asuntos Sociales, 57. (p. 75).

${ }^{32}$ Como señala Maestro Buelga "la homogeneidad de las condiciones sociales no era una necesidad para la construcción del mercado, lo que permitía marginalizar las demandas de homogenización social y asentar la intervención comunitaria en la integración negativa". Maestro Buelga, G. (2006). El impacto de la ampliación de la UE sobre el modelo social europeo. Revista de Derecho Comunitario Europeo, 23. (p. 8). Para una mayor perspectiva de la clara orientación económica del TCEE véanse, entre otros, Aparicio Tovar, J. (2005). Op. Cit. (pp. 26-27); Pérez de los Cobos Orihuel, F. (1994). El derecho social comunitario en el Tratado de la Unión Europea. Madrid: Civitas. (pp. 19-23); Mengozzi, P. (1982). European Community Law: from common market to European Union. London: European Law Library. Wolters Kluwer Academic Publishers Group. (pp. 7-13); Cruz Villalón, J. (2000). La dimensión social de la Unión Europea: surgimiento y evolución. En Cruz Villalón, J. y Pérez del Río, T. (Coords.). Una aproximación al Derecho Social Comunitario. Madrid: Editorial Tecnos. (p. 13). 
33 Montoya Melgar, Galiana Moreno y Sempere Navarro señalan que "el Tratado de la CEE y su desarrollo comunitario presentan resultados sociales mucho más numerosos e importantes, pese a que en rigor no haya logrado establecerse aún una política social, y menos un Derecho social, completos en el orden comunitario. Con todo, desde un principio, los objetivos sociales del Tratado de la CEE encomendados a la Comunidad han superado en mucho a los de los otros dos tratados comunitarios". Montoya Melgar, A., Galiana Moreno, J.M. y Sempere Navarro, A.V. (1994). Derecho Social Europeo: Madrid: Editorial Tecnos. (p. 29). Raepenbusch apunta que "aun cuando no se puede ignorar la vocación inicial esencialmente económica de los Tratados por los que se crearon las CE, los objetivos sociales latu sensu figuran también en el primer plano de los objetivos comunitarios". Van Raepenbusch, S. (2011). Op. Cit. (p. 111). Por su parte, Cruz Villalón alude a ciertos "oasis de socialidad” señalando que "la supresión entre los Estados miembros de los obstáculos a la constitución de ese gran mercado y, en particular, de los obstáculos a la libre circulación de personas, servicios y capitales, constituirá una hábil excusa para una intervención incipiente de las instituciones comunitarias en aspectos concretos de las relaciones laborales". Cruz Villalón, J. (2000). Op. Cit. (p. 14). Una aproximación a las disposiciones sociales del Tratado de Roma en Anónimo (1957). Politique sociale et Marché commun. Revista Droit Social, 12. (pp. $608-621$ ).

34 Un concepto claramente excesivo si se tiene en cuenta que el texto del TCEE garantizaba esta libertad únicamente a los trabajadores. Dans Álvarez de Sotomayor, L. (2009). La progresiva ampliación del campo de aplicación personal en la normativa social comunitaria: extensión y límites del derecho de libre circulación. En AA.VV. Los mercados laborales y las políticas sociales en Europa. XX Congreso Nacional de Derecho del Trabajo y de la Seguridad Social. Madrid: Ministerio de Trabajo e Inmigración. (p. 153).

35 La finalidad de las disposiciones sociales comunitarias ha sido casi siempre la de igualar los costos sociales de las empresas de los distintos países comunitarios para evitar que se alterase, por la vía de una legislación menos avanzada en un Estado miembro, la libre competencia entre las mismas". Colina Robledo, M., Ramírez Martínez, J.M. y Sala Franco, T. (1995). Derecho Social Comunitario. Valencia: Tirant lo Blanch. (p. 70).

${ }^{36}$ El artículo 69.1 TCECA aludía, ya en su momento, al compromiso de los Estados miembros a suprimir cualquier tipo de restricción "por motivos de nacionalidad, respecto del empleo, en las industrias del carbón y del acero".

37 Salas Porras señala la importancia de los principios de efecto directo y de reconocimiento mutuo como garantía para el efectivo disfrute de la libertad de circulación. Salas Porras, M. (2019). Las libertades de circulación y establecimiento de trabajadores. Aportaciones para el avance de la dimensión social europea desde el enfoque transnacional. Navarra: Aranzadi. (pp. 54-56).

${ }^{8}$ Sobre la finalidad económica de la libre circulación de trabajadores véase, entre otros, Fernández Márquez, O. (2016). Libre circulación de personas por el territorio comunitario. En García Murcia, J. (Dir.). Libertades de circulación y derechos de protección social en la Unión Europea. Lisboa: Editorial Juruá. (pp. 48-49): “Es lugar común que la libre circulación aparece en Europa inicialmente consagrada [...] como libre circulación de trabajadores, es decir, como principio o pauta de liberalización del flujo de un recurso económico productivo como es la fuerza de trabajo por el interior del territorio comunitario". Linde Paniagua, E. (2003). La libre circulación de los trabajadores versus libre circulación de las personas. La ciudadanía europea. Revista de Derecho de la Unión Europea, 5. (pp. 15-16): “Habida cuenta de que el Tratado de Roma de 1957 creaba una comunidad económica no resultaba extraño que las libertades que se creaban fueran, también, de naturaleza económica, con el fin de alcanzar los objetivos económicos explícitos que figuraban en el artículo 2 del mencionado Tratado". Vrillon, M.B. (1966). La libre circulation des travailleurs de la communauté économique européene dans l'optique du comité consultatif de la libre circulation. Revista Droit Social, 5. (p. 279): “Du point de vue économique, la libre circulation du “facteur travail”, c'est-a-dire de la main-d'euvre, est indispensable dans un contexte où les autres éléments productifs, capitaux et marchandises, circulent eux aussi librement".

39 Recuérdese, por ejemplo, lo recogido en el artículo 69.4 TCECA sobre la necesidad de buscar "cuantas soluciones sigan siendo necesarias a fin de que las disposiciones relativas a la seguridad social no constituyan un obstáculo para los movimientos de la mano de obra".

40 Todas ellas "medidas complementarias" a la libre circulación de trabajadores. Plender, R. y Pérez Santos, J. (1985). Introducción al Derecho Comunitario Europeo. Madrid: Editorial Civitas. (p. 142). 
${ }^{41}$ Debe apuntarse que, tal y como señala Raepenbusch, "en el Tratado no existe ninguna disposición en la que se prevea específicamente la armonización de los regímenes de Seguridad Social, considerados ante todo como propios de la competencia de los Estados miembros. En realidad en el ánimo de los autores del Tratado, este medio de actuación [... ] sólo se debía emplear con el fin de eliminar todo lo que pudiera perturbar artificialmente el libre juego de la competencia; aparte de este objetivo, no se juzgó que la armonización fuera necesaria, ni incluso deseable”. Van Raepenbusch, S. (2011). Op. Cit. (pp. 117-118). Sobre el concepto de "armonización" y su alcance en materia social, véase también Gárate Castro, J. (2010). Transformaciones en las normas sociales de la Unión Europea. Madrid: Editorial Universitaria Ramón Areces. (pp. 29-78).

${ }^{42}$ Artículos que, en opinión de Watson, tenían un escaso impacto real "articles 117-122 were vague and repetitious, conferring no real powers upon the Community institutions, and little by way of direct rights upon the community citizens". Watson, P. (2009). EU Social and Employment Law. New York: Oxford University Press. (p. 47).

43 En detalle sobre la armonización de las legislaciones sociales en el proceso de integración europea, véase RodríguezPiñero Royo, M.C. y Castellano Burguillo, E. (2005). La armonización comunitaria y el modelo social europeo. Revista Documentación Laboral, 74. (pp. 9-42).

${ }^{44}$ Acerca del alcance de las “técnicas" o "procesos legales” de armonización, aproximación y coordinación que contemplaba el Tratado de Roma, véase Watson, P. (1980).Op. Cit. (pp. 30-57). En la misma línea, sobre la armonización, coordinación o articulación de la pluralidad de sistemas de Seguridad Social, Miranda Boto, JM. (2011). “La competencia comunitaria en materia de Seguridad Social”. Noticias de la Unión Europea, 319. (pp. 5-8).

45 Pérez de los Cobos Orihuel, F. (1994). Op. Cit. (p. 27).

${ }^{46}$ Sobre el "carácter programático" del artículo 117 TCEE, Van Raepenbusch, S. (2011). Op. Cit. (pp. 125-126).

47 Nogueira Guastavino, M. (2012). La progresiva política social de la Unión Europea. En Nogueira Guastavino, M., Fotinopoulou Basurko, O. y Miranda Boto, J.M. (Dirs.). Lecciones de Derecho Social de la Unión Europea. Valencia: Tirant lo Blanch. (p. 29). Igual consideración en, Pérez de los Cobos Orihuel, (1994). Op. Cit. (pp. 26-27).

${ }^{48}$ Con una visión expansiva, Lasa López sugiere que "el artículo 117 no subordina la armonización de las legislaciones a la existencia de una desigualdad que afecte a la competencia, es decir, no está limitado a las disposiciones que tienen una incidencia sobre el mercado común. De acuerdo con este planteamiento, el artículo 117 se desvincula de los condicionamientos del mercado, presentándose como una disposición social autónoma”. Lasa López, A. (2012). Los derechos sociales en el constitucionalismo de mercado: aporías de la dimensión social en la Unión Europea. Bilbao: Servicio Editorial de la Universidad del País Vasco. (p. 92).

49 El artículo 118 TCEE establecía como mecanismos a utilizar por la Comisión, para el acercamiento de los Estados miembros en estas cuestiones, "estudios, dictámenes y la organización de consultas, tanto para los problemas que se planteen a nivel nacional como para aquellos que interesen a las organizaciones internacionales".

${ }^{50}$ Pérez de los Cobos Orihuel, F. (1994). Op. Cit. (p. 30): “El estado de la cuestión concluido el período transitorio venía dado por la inaplicación generalizada del precepto en cuestión, es decir, por la persistencia en el conjunto de los Estados miembros de importantes discriminaciones salariales. [... en vísperas del término previsto, los representantes de los Estados miembros, reunidos en el seno del Consejo, adoptaron la decisión de retrasarlo". ${ }^{51}$ El Capítulo 2, Sección 2 del Informe Spaak, relativo a la armonización de legislaciones, recogía la necesidad de los gobiernos de "hacer un esfuerzo especial para la armonización progresiva de las legislaciones nacionales que afectasen a la equidad de salarios entre hombres y mujeres, la duración de la jornada de trabajo y la duración de las vacaciones retribuidas".

52 “El más antiguo de los Fondos Estructurales". Gomis Vidal, P.L. (1999). Op. Cit. (p. 42). En mayor profundidad sobre su naturaleza, regulación, objetivos y funcionamiento véase, Gárate Castro, J. (1987). Apuntes sobre la regulación y funcionamiento del Fondo Social Europeo. Revista Española de Derecho del Trabajo, 30. (pp. 243-267); García Murcia, J. y Menéndez Sebastián, P. (2004). El Fondo Social Europeo. Revista Noticias de la Unión Europea, 234. (pp. 91-97); Gárate Castro, J. (1987). El Fondo Social Europeo: configuración actual. Revista Actualidad Laboral, 2. (pp. 1913-1928). 
53 Para López-Romero González, su creación dio lugar al "principal arma de las Comunidades Europeas para combatir el desempleo". López-Romero González, P. (2003). La política de empleo en la Unión Europea. Revista Universitaria de Ciencias del Trabajo, 3-4. (p. 735); mientras que para Fernández Rodríguez el Fondo Social Europeo fue "el principal instrumento de la Unión en el desarrollo de la política social y, en particular en el desarrollo de los recursos humanos y la mejora del funcionamiento del empleo en la Unión". Fernández Rodríguez, C. (2003). El Fondo Social Europeo. Revista de Derecho de la Unión Europea, $5,2^{\circ}$ semestre. No obstante, tal y como señalan Ribas, Jonczy y Séché, "el Fondo Social no debía ser una especie de asistencia al desempleo o de seguro de desempleo, sino un medio de lucha contra la causa misma del desempleo". Ribas, J.J., Jonczy, M.J. y Séché, J.C. (1980). Op. Cit. (p. 451).

${ }^{54}$ Fraile, J.M. (1994). El Fondo Social Europeo. Cuadernos de Relaciones Laborales, 4. Madrid: Editorial Complutense. (p. 61): "El Fondo Social Europeo [... ] es sin duda el elemento más importante de que dispone la Comunidad para contribuir desde el capítulo social al proceso de integración económica de Europa". En la misma línea, Colina Robledo, Ramírez Martínez y Sala Franco señalan que "la constitución del FSE ha sido sin duda la principal medida comunitaria llevada a cabo en materia de política de empleo". Colina Robledo, M., Ramírez Martínez, J.M. y Sala Franco, T. (1995). Op. Cit. (p. 240).

55 Como señalan Colina Robledo, Ramírez Martínez y Sala Franco, "el FSE ha sufrido una importante evolución marcada por el realismo y por el carácter histórico social del ordenamiento comunitario e inspirada en el principio de solidaridad, adaptándose a las nuevas situaciones del mercado de trabajo, pasando de una fase inicial más bien pasivaen que se limitaba a reembolsar parte de los gastos efectuados por los Estados miembros en ayudas de reeducación profesional y de reinstalación a trabajadores en paro y, para el mantenimiento de su nivel de retribución, a trabajadores afectados por reconversión-, a una política más activa, coordinada a las políticas propias de la Comunidad y orientada a la promoción del empleo de algunos colectivos, principalmente de jóvenes y de desempleados de larga duración". Ibídem. (p. 240). A este respecto, Ribas, Jonczy y Séché señalan que "los autores del Tratado creyeron oportuno no limitar la intervención del Fondo, como se había inicialmente previsto exclusivamente a las operaciones derivadas de los cambios estructurales, sino extenderlo también a las operaciones efectuadas en razón de circunstancias coyunturales". Ribas, J.J., Jonczy, M.J. y Séché, J.C. (1980). Op. Cit. (p. 451).

${ }^{56}$ Artículo 124 TCEE: "La administración del Fondo corresponderá a la Comisión. En dicha tarea, la Comisión estará asistida por un Comité, presidido por un miembro de la Comisión y compuesto por representantes de los Gobiernos, de las organizaciones sindicales de trabajadores y de las asociaciones empresariales".

${ }^{57}$ Con carácter general, sobre los supuestos de intervención de Fondo Social Europeo y su evolución a lo largo de los años, Ribas, Jonczy y Séché. (1980). Op. Cit. (pp. 451-517).

${ }^{58}$ En una cuantía correspondiente al 50\% de los gastos destinados por ese Estado a tales fines. En detalle, Ibídem. (pp. 456-457).

59 En palabras de Sala Franco y Ramírez Martínez, la tarea principal del Fondo Social Europeo fue, al menos inicialmente, "facilitar esa libertad de circulación, ayudando a trasladarse y a adquirir otra formación profesional". Sala Franco, T. y Ramírez Martínez, J.M. (1986). Introducción al Derecho social comunitario. Valencia: Tirant lo Blanch. (p. 65).

${ }^{60}$ Sobre la acción del Fondo Social Europeo en materia de movilidad geográfica y profesional, véase Montoya Melgar, A., Galiana Moreno, J.M. y Sempere Navarro, A.V. (1988). Instituciones de Derecho Social Europeo. Madrid: Editorial Tecnos. (pp. 98-99).

${ }^{61}$ Martín Valverde, A. (1986). El Fondo Social y la política de empleo en la Comunidad Europea. Bilbao: La Ley. (p. 16). ${ }^{62}$ Sobre su aportación al fomento de la igualdad de oportunidades entre mujeres y hombres, véase Hierro Hierro, F.J. (2004). La contribución del Fondo Social Europeo al fomento de la igualdad de oportunidades entre mujeres y hombres. Tribuna Social: Revista de Seguridad Social y Laboral, 57. (pp. 47-54). Con carácter general, acerca de la evolución de su campo de aplicación personal, véase Domínguez Garrido, J.L. (1986). La problemática del Fondo Social Europeo. Revista Documentación Laboral, 19. (pp. 56-77).

${ }^{63}$ Lo que, en opinión de Domínguez Garrido, suponía unas "condiciones muy restrictivas para la intervención del Fondo". Domínguez Garrido, J.L. (1985). La reforma de 1983 del Fondo Social Europeo. Madrid: Ministerio de Trabajo y Seguridad Social, Informes y Documentos. (p.11).

64 "La historia del Fondo ha sido la de sus reformas, la cuales siempre han tenido la misma finalidad: hacer de él un instrumento comunitario que cada vez dé mejores resultados de cara a una política de empleo dinámica". Fraile, J.M. (1994). Op. Cit. (p. 62). 
${ }^{65}$ DO N P056, de 31/08/1960, 1189/60.

${ }^{66}$ Definía también los conceptos de reeducación profesional (artículo 3), reinstalación (artículo 6 ) y reconversión (artículo 9).

${ }^{67}$ En opinión de Ribas, Jonczy y Séché, esta exigencia de tres meses de inscripción consecutiva a los menores de 18 años se estableció para garantizar que el Fondo "no sea inducido a intervenir a favor de la formación profesional normal de los jóvenes que salen de la escuela”. Ribas, J.J., Jonczy, M.J. y Séché, J.C. (1980). Op. Cit. (p. 453).

${ }^{68}$ Para la determinación de una situación de subempleo había que acudir al artículo 1 del Reglamento (CEE) n 12 , de 18 de febrero de 1964, donde se establecían como supuestos caracterizadores de esta situación los de "trabajadores desempleados que, de manera involuntaria, hubieran estado empleados durante los tres meses anteriores por no más de la mitad de las horas de trabajo consideradas normales o, durante seis meses antes de la misma fecha, durante un máximo de tres cuartos de ese período", "trabajadores empleados en una empresa cuyo cierre o reducción de actividad, decidida para una fecha específica, eventualmente conllevará el cese de la actividad de ese trabajador" y la de "trabajadores por cuenta propia, y/o los ayudantes familiares, obligados a renunciar a su actividad en el sector agrícola”. Reglamento (CEE) n 12, de la Comisión, de 18 de febrero de 1964, por el que se establecen las condiciones que especifican la situación manifiesta de subempleo prolongado en el sentido del artículo 2, apartado 3, letra a), del Reglamento (CEE) $n^{\circ} 9$ del Consejo, relativo al Fondo Social Europeo. DO № 32, 22/02/1964.

${ }^{69}$ Según lo dispuesto en el propio artículo 2, la acreditación de esta situación de subempleo se obtenía con la inscripción durante un período de dos años a partir de la fecha de entrada en vigor del Reglamento (CEE) $n^{\circ} 9$ o, en ausencia de dicho registro y para trabajadores de al menos 18 años de edad, con la certificación de esta situación, durante al menos seis meses, por parte del servicio público de empleo competente.

${ }^{70}$ Martín Valverde, A. (1986). Op. Cit. (p. 33): "El artículo 128 del Tratado de Roma expresa la voluntad comunitaria de intervenir con cierta intensidad en el campo de la formación profesional".

${ }^{71}$ El artículo 193 TCEE enumeraba a "productores, agricultores, transportistas, trabajadores, comerciantes y artesanos, así como de las profesiones liberales y del interés general". En detalle, Tessier, J. (1957). Le Conseil économique et social européen. Revista Droit Social, 11. (pp. 541-550).

${ }^{72}$ Maldonado Gago, J. (1997). Política Social de la Unión Europea. Revista de Estudios Políticos Nueva Época, 95. (p. 264); Miranda Boto, J.M. (2008). Los humildes orígenes de la política social comunitaria. Revista Dereito, Vol. 17, 2. (pp. 155-170).

73 Turín, 19 de octubre de 1961.

${ }^{74}$ Roma, 4 de noviembre de 1950.

75 No obstante, en opinión de Sevilla Merino y Ventura Franch, “el incremento de las políticas sociales de la Unión Europea ha tenido como referente la Carta Social Europea". Sevilla Merino, J. y Ventura Franch, A. (2005). Op. Cit. (p. 84). En la misma línea, Ojeda Avilés destaca el carácter inspirador que la Carta ha tenido para otros instrumentos internacionales, a pesar del desmerecimiento que esta ha tenido por parte de la OIT y de la UE "que han restado protagonismo a sus preceptos sobre la relación laboral que [... ] viven en la actualidad en cierta penumbra". Ojeda Avilés, A. (2013). Derecho transnacional del trabajo. Valencia: Tirant lo Blanch, Valencia. (pp. 144-145).

${ }^{76}$ Prieto Suárez, R. (2008). Op. Cit. (p. 356). Sobre su evolución y paulatina asunción, véase también Jimena Quesada, L. (2009). La Carta Social Europea y la Unión Europea. Revista Europea de Derechos Fundamentales, 13, $1^{\circ}$ semestre. (pp. 389 y ss).

77 Para mayor análisis, véase Rodríguez-Piñero y Bravo-Ferrer. M. (1978). Op. Cit. (pp. 53 - 69); Valticos, N. (1963). La Chartre Sociale Européene. Sa structure, son contenu, le contrôle de son application.Revista Droit Social, 8. (pp. 466482).

${ }^{78}$ Art. 12.4.a).

${ }^{79}$ Art. 12.4.b).

${ }^{80}$ Ruiz de la Cuesta Fernández habla de unos primeros años de la nueva Europa "al margen del empleo". Ruiz de la Cuesta Fernández (2004). Empleo y desempleo en la Unión Europea: del desinterés a la prioridad absoluta. En Desempleo. XIV Congreso Nacional de Derecho del Trabajo y de la Seguridad Social. Madrid: Ministerio de Trabajo y Asuntos Sociales. (p. 533). 
81 “Ello se explica, recuérdese, porque el objetivo inicial y exclusivo de las Comunidades Europeas era esencialmente económico: la creación de un mercado común, donde la libre circulación de trabajadores se erigía en una libertad económica más junto a la de capitales, mercancías y servicios”. Dans Álvarez de Sotomayor, L. (2009). Op. Cit. (p. 153). En la misma dirección, Masala y Valdés Dal-Re justifican esta "asimetría” inicial entre el componente económico y el componente social "by a clear separation of powers and tasks between the European Community (the market) and the Member States (the social)". Masala, P. y Valdés Dal-Re, F. (2019). The future of Social Europe and of European Integration at a Crossroads: How can we recover and enforce solidarity as a fundamental principle of European Constitutional Law (or die)? European Papers, Vol. 4, 1. (p. 259).

82 Un ejemplo más de lo que Martínez Yáñez ha definido como "la irresuelta tensión entre el contenido económico y social del proyecto europeo”. Martínez Yáñez, N.M. (2015). La coordinación de las políticas sociales y de empleo en el vórtice de la gobernanza económica europea. Revista de Derecho Comunitario Europeo, 52. (p. 949).

${ }^{83}$ Martín Valverde, A. (1986). Op. Cit. (p. 15): “Las subvenciones o ayudas no reembolsables que otorga el FSE no tienen, sin embargo, la condición de prestaciones sociales en el sentido usual de la expresión, es decir, no están destinadas a la cobertura de situaciones de necesidad de concreción individual, consistentes en un exceso de gastos o en un defecto de ingresos".

84 Luxemburgo, 17 de febrero de 1986, aunque sólo por nueve países, los restantes lo hicieron unos días después, el 28 de febrero. Para una aproximación al proceso de elaboración y su aplicación véase Sánchez Fernández de Gata, D. (1995). Los caminos de la Unión Europea: los procesos de elaboración del Acta Única y del Tratado de Maastricht. Revista Noticias de la Unión Europea, 131. (pp.10-18).

85 En opinión de Pedrosa Sanz "no introdujo cambios significativos en su articulado sobre política social, más bien la limitó formalmente”. Pedrosa Sanz, R. (2009). El desarrollo histórico de la Política Social de la Unión Europea y su estado actual. Estudios de Economía Aplicada, Vol. 27-3. (p. 616). Sin embargo, otros autores consideran que sí lo supuso a otros niveles. Tal y como señalan Mangas Martín y Liñán Nogueras, el AUE supuso una de las más amplias reformas, afectando "tanto a Tratados fundacionales, como a posteriores Tratados modificativos, y se ha articulado en un texto convencional único", "las reformas introducidas por el AUE afectaron a todas las Instituciones". Mangas Martín, A. y Liñán Nogueras, D.J. (1996). Op. Cit. (pp. 23-24). A este respecto, Cabeza Pereiro señala que “el Derecho originario ganó en contenidos sociales en el año 1986. Este contenido se produce en el plano sustantivo, pero sobre todo en el plano procedimental”. Cabeza Pereiro, J. (2000). La cuestión social en el Derecho originario de la Unión Europea. Revista Documentación Laboral, 63. (p. 32). Por su parte, Monereo Pérez y Fernández Bernat otorgan al AUE la condición de "elemento fundamental" en el desarrollo de la política social y de empleo. Monereo Pérez, J.L. y Fernández Bernat, J.A. (2017). El pilar europeo de los derechos sociales: un mecanismo insuficiente para garantizar la dimensión social. La Ley Unión Europea, 49.; mientras que Maracuello Moreno, en la misma dirección, considera que “este documento inspirará toda la política social”. Maracuello Moreno, M.M. (2001). La política social de la Unión Europea. Revista Noticias de la Unión Europea, 195. (p. 60).

${ }^{86}$ Sobre la gestación del Acta Única Europea, Bonet Marco, E. (1988). Introducción al Acta Única Europea. Madrid: ESIC Editorial, Colección Estudios, 13. (pp. 26 y ss).

87 Artículos 21 y 22 del AUE.

88 “El AUE tiene además importancia por inaugurar la referencia al medio de trabajo en conexión con la seguridad y salud, lo cual permitirá salir de los estrechos márgenes de un enfoque puramente sanitario para incursionar en el entorno estructural al poner de relieve la estrecha conexión entre, por ejemplo, una jornada con descansos adecuados y la menor incidencia de accidentes debidos a la fatiga”. Ojeda Avilés, A. (2013). Op. Cit. (p. 202). En la misma línea interpretativa aperturista, Bercusson, B. (2009). European Labour Law. Cambridge: Cambridge University Press. (p.125). 89 Beneyto sostiene que "el artículo 118A, define un objetivo general de política social europea, la mejora del medio de trabajo para proteger la seguridad y salud de los trabajadores y, paralelamente, un objetivo instrumental, la armonización por la vía del progreso de las condiciones existentes en ese ámbito”. Beneyto, J.M. (1989). Europa 1992. El Acta Única Europea: mercado interior y cooperación política europea. Madrid: Editorial Civitas. (p. 171). Sobre este particular, Ojeda Avilés destaca el "enorme avance" que el nuevo artículo 118A supuso para la aproximación de legislaciones en esta materia. Ojeda Avilés, A. (2013). Op. Cit. (p. 202).

90 "A propuesta de la Comisión, en cooperación con el Parlamento Europeo y previa consulta al Comité Económico y Social”. Artículo 118A.2, introducido por el 21 AUE. 
${ }^{11}$ En palabras de Bonet Marco, "el gran avance ha sido la posibilidad de adoptar las directivas por mayoría cualificada". Bonet Marco, E. (1988). Op. Cit. (p. 65).

$9^{2}$ La utilización de esta técnica de mínimos implica, a juicio de Lasa López, "un retroceso en el auspiciado ingreso de los derechos sociales en el escenario europeo”. Lasa López, A. (2012). Op. Cit. (p. 102).

93 No obstante, tal y como señala Pérez de los Cobos Orihuel, "si antes de la entrada en vigor del Acta Única, la adopción de directivas, cuya finalidad fuese esta aproximación, sólo podía producirse, por unanimidad, y siempre y cuando las disposiciones a aproximar tuvieran una incidencia directa en el establecimiento del mercado común [... ], tras la aprobación del Acta Única, el Consejo puede, por mayoría cualificada, en cooperación con el Parlamento Europeo y previa consulta al Comité Económico y Social, adoptar cuantas medidas relativas a la aproximación en cuestión estime oportunas para el establecimiento y el funcionamiento del mercado común". Sobre esta nueva “división competencial" y el "aligeramiento" de los requisitos en materia de aproximación de legislaciones introducidos por el nuevo artículo 118 . Pérez de los Cobos Orihuel, F. (1994). Op. Cit. (pp. 49-55). En la misma línea, Cruz Villalón resalta la proliferación normativa sobre estas cuestiones a raíz de la introducción de la mayoría cualificada por el AUE, llegando a "forzar la letra del Tratado, procediendo a aprobar una serie de Directivas sobre materias laborales que sólo de forma muy lateral afectaban a la materia de seguridad y salud en el trabajo”. Cruz Villalón, J. (2000). Op. Cit. (pp. 18-19).

94 La intensidad de la encomienda de esta tarea a la Comisión se limitaba a un simple "procurará desarrollar" en el texto del nuevo artículo 118B. Sobre la ambigüedad de esta disposición, así como de las distintas interpretaciones que ha generado, Pérez de los Cobos Orihuel, F. (1994). Op. Cit. (pp. 55-61).

95 Sobre este particular, Bonet Marco apunta la posibilidad de alcanzar "convenios entre los partícipes sociales en el ámbito comunitario". Bonet Marco, E. (1988). Op. Cit. (p. 66). Por su parte, Gomis Vidal señala este nuevo aspecto introducido por el AUE como la "primera base jurídica a lo que se ha dado en llamar el <<diálogo social europeo>>”. Gomis Vidal, P.L. (1999). Op. Cit. (p. 44).

${ }^{96}$ En detalle, sobre la gestación y alcance social de los artículos 118A y 118B, introducidos por el AUE, véase Beneyto, J.M. (1989). Op. Cit. (pp. 170-180); Pons Carmena, M. (2015). Modelo social europeo y protección de los derechos sociales fundamentales. Madrid: Editorial Reus. (pp. 24-30).

97 Pese a su carácter "político - indicativo" en opinión de Bar Cendón, el texto de la Carta Comunitaria de los Derechos Sociales Fundamentales de los Trabajadores "es novedoso y avanzado en su regulación y prevé derechos referidos a la libre circulación, el empleo y la remuneración, la protección social, la libertad de asociación y negociación colectiva, la formación profesional, la igualdad de trato entre hombres y mujeres, la información, consulta y participación de los trabajadores, la protección de la salud y de la seguridad en el lugar de trabajo, la protección de los niños y de los adolescentes, las persona de edad avanzada, y los minusválidos". Bar Cendón, A. (2012). Op. Cit. (p. 35). Por su parte, Fernández Docampo destaca el reconocimiento a nivel comunitario de los derechos de asociación, negociación colectiva, información, consulta y participación de los trabajadores a través de una disposición que define como “atípica”, en alusión a la Carta Comunitaria de los Derechos Sociales Fundamentales de los Trabajadores. Fernández Docampo, B. (2006). La participación de los trabajadores en el Derecho Social Comunitario. Valencia: Tirant lo Blanch. (p. 16).

98 Pérez del Río, T. (1991). La dimensión social del Mercado Único Europeo. Revista Española de Derecho del Trabajo, 47. (pp. 392-393).

99 Y de los Estados miembros al intentar “dar contenido a la dimensión social de la Unión Europea, marcando el camino para establecer prácticas regionales mediante las cuales especificar el grado y nivel de cohesión económicosocial”. Fernández Riquelme, S. (2009). Política Social en la Unión Europea: del Estado del Bienestar a la Europa social. La Razón Histórica. Revista Hispanoamericana de Historia de las Ideas, 9. (p. 33).

${ }^{100}$ En mayor profundidad sobre la gestación, alcance jurídico y contenido social de la Carta Comunitaria de los Derechos Sociales Fundamentales de los Trabajadores véase Monereo Pérez, J.L. (1992). Carta comunitaria de derechos sociales fundamentales de los trabajadores (I). Revista Española de Derecho del Trabajo, 56. (pp. 843-897) y Monereo Pérez, J.L. (1993). Carta comunitaria de derechos sociales fundamentales de los trabajadores (II). Revista Española de Derecho del Trabajo, 57. (pp. 61-89).

${ }^{101}$ Firmado en febrero de 1992, entró en vigor en noviembre de 1993. Sobre su contexto y alcance, véase Fernández Navarrete, D. (2018). Historia de la Unión Europea. De los orígenes al Brexit. Madrid: UAM Ediciones. (pp. 139-158). 
102 "The Maastricht Treaty on European Union dealt extensively with social policy, in giving it a firm treaty base for the first time". Ashiagbor, D. (2001). EMU and the Shift in the European Labour Law Agenda: From "Social Policy" to “Employment Policy”. European Law Journal, Vol. 7,3. (p. 324). Sobre este particular, Bercusson atribuye al Tratado de Maastricht un cambio fundamental en materia social. Bercusson, B. (2009). Maastricht: A fundamental change in European labour law. En Labour Law an Social Europe. Selected writings of Brian Bercusson. Brussels: European Trade Union Institute (ETUI). (pp. 89-114). Idéntica valoración en Bercusson, B. (2009). Op. Cit. (p. 141 y ss). Con la misma percepción, Miranda Boto califica este hecho como el "punto crítico" frente a la frigidez social anterior. Miranda Boto, J.M. (2003). El principio de subsidiariedad en el ordenamiento comunitario y sus aplicaciones en materia social. Revista del Ministerio de Trabajo y Asuntos Sociales, 47. (p. 116).

103 Sobre las reticencias de su inclusión, véase Cruz Villalón, J. (2000). Op. Cit. (pp. 20-23). También sobre esta cuestión, Galantino señala "La tematica della política sociale comunitaria ha constituito certamente il punto piú delicato della trattative che hanno preceduto il Tratato di Maastricht sull'Unione Europea”. Galantino, L. (2001). Diritto Comunitario del Lavoro. Torino: G. Giappicheli Editore. (p. 45).

${ }^{104}$ Acerca de su contenido y puesta en práctica, véase Peredo Linacero, J.A. (1994). Algunas consideraciones sobre la puesta en práctica del Acuerdo sobre la Política Social del Tratado de Maastricht. Cuadernos de Trabajo Social, 7.

Madrid: Editorial Universidad Complutense. (pp. 109-120).

105 Nogueira Guastavino habla de un "decisivo impulso hacia la construcción de una Europa social” y de "la normativa más ambiciosa”, si bien, también apunta al cuestionado valor jurídico del Acuerdo. Nogueira Guastavino, M. (2012). Op. Cit. (p. 35). Para Cruz Villalón "constituye un salto cualitativo definitivo en el desarrollo del Espacio social Europeo [...]. Por primera vez, a través de un texto vinculante y no meramente programático de intenciones, se extiende el área de actuación normativa de las instituciones comunitarias al conjunto básico de la legislación laboral”. Cruz Villalón, J. (2000). Op. Cit. (p. 21).

${ }^{106}$ Como apunta Ruiz de la Cuesta, "a partir de esta incorporación de los objetivos sociales se permite a las instituciones comunitarias actuar en vía legislativa, como complemento y ayuda a las acciones de los Estados miembros en los ámbitos mencionados, a través de la mayoría cualificada, abandonándose, por lo tanto, la rígida exigencia de unanimidad con el fin de agilizar la intervención comunitaria en esta materia”. Ruiz de la Cuesta, S. (2004). Op. Cit. (p. 536).

107 Ibídem, p. 536.

108 “Noción que comprende la generalidad del tratamiento normativo de la relación de trabajo salvo las expresamente excluidas o vinculadas a la regla de la unanimidad". Nogueira Guastavino, M. (2012). Op. Cit. (p. 36).

109 En opinión de Pérez de los Cobos, "el concepto de <<excluidos del mercado laboral>> comprende, especialmente, a los colectivos de marginados en el mercado, como jóvenes, trabajadores de edad avanzada, parados de larga duración y minusválidos", remarcando los efectos "especialmente perniciosos que el desempleo tiene sobre estos colectivos". Pérez de los Cobos Orihuel, F. (1994). Op. Cit. (pp. 115-116).

${ }^{110}$ Nogueira Guastavino, M. (2012). Op. Cit. (p. 36).

111 Sobre la contradicción entre la importancia de las cuestiones y el mecanismo establecido para la adopción de acuerdos, véase Rodríguez-Piñero Royo, M. y Castellano Burguillo, E. (2001). La política de empleo de la Unión Europea. Trabajo: Revista Andaluza de Relaciones Laborales, 10. (p. 18): "Resulta contradictorio que, por una parte, según el artículo 2.3 de este Acuerdo, se exija la unanimidad en el Consejo de Ministros de la Unión Europea, para la aprobación de cualquier norma que tenga por objeto la coordinación de las políticas nacionales, cuando dicha actuación tenga relación con materia como las contribuciones financieras dirigidas al fomento del empleo y a la creación de empleo y por otra parte, se exija sólo mayoría cualificada para la intervención en materia como la mejora del entorno de trabajo, de las condiciones de trabajo, la igualdad de oportunidades entre hombres y mujeres o la integración de las persona excluidas, etc".

${ }^{112}$ Ibídem. (p. 18).

113 Consejo Europeo de Essen (1994), Consejo Europeo de Cannes (1995), Consejo Europeo de Turín (1996), Consejo Europeo de Florencia (1996) y Consejo Europeo de Dublín (1996). Sobre el tratamiento que a la cuestión del empleo se dio en cada uno de ellos, véase Ruiz de la Cuesta, S. (2004). Op. Cit. (pp. 537-539); Palomino Saurina, P. (2013). La política de empleo en la Unión Europea a través de los Consejos Europeos. Revista Relaciones Laborales, 4. Con carácter general, sobre la importancia del Consejo Europeo en materia social, Miranda Boto, J.M. (2009). Mehr Papiere Und Beamten? La creciente importancia del Consejo Europeo en materia social. Revista Temas Laborales, 102. (pp. 89-102). 
${ }^{114}$ Libro Blanco sobre el Crecimiento, Competitividad y Empleo: Retos y Pistas para entrar en el siglo XXI. Luxemburgo: Oficina de Publicaciones Oficiales de las Comunidades Europeas. Suplemento 6/93.

115 "Dicho informe constituyó el primer intento serio de coordinación de las políticas nacionales de lucha contra el desempleo”. Márquez Prieto, A. (2001). La protección por desempleo en España y otros Estados europeos. Madrid: Ministerio de Trabajo y Asuntos Sociales, Subdirección General de Publicaciones. (p. 27).

116 “El desempleo en la Comunidad ha alcanzado proporciones alarmantes. Tras cinco años de constante mejora, el número de desempleados comenzó a incrementarse nuevamente, de manera significativa, a principios de la década de los noventa. Además, el desempleo comunitario se caracteriza por el alto porcentaje de paro de larga duración, que se aproxima a la mitad del total, y por su especial incidencia entre los trabajadores poco cualificados". Libro Blanco sobre el Crecimiento, Competitividad y Empleo: Retos y Pistas para entrar en el siglo XXI. (1993). Op. Cit. (p. 44).

117 Ibídem. (p. 134).

118 Ibídem. (p. 135).

119 Desempleo juvenil, femenino y de larga duración.

120 "No sólo incluyen los gastos directos de la ayuda de la seguridad social a los desempleados sino también los ingresos fiscales no recaudados que los desempleados pagarían de sus rentas si estuvieran trabajando; mayor carga en los servicios sociales; mayores niveles de pobreza, delincuencia y problemas de salud, así como de fracaso escolar". Ibídem. (p. 138).

121 "El actual desempleo comunitario se explica en parte por una débil tasa de crecimiento económico y en parte por la falta de flexibilidad del mercado de trabajo", "los cambios sociales y demográficos son también importantes". Ibídem, pp. 138-139.

122 Sobre las acciones específicas, el Libro Blanco apuntaba a los costes laborales, la flexibilidad del mercado de trabajo, el desarrollo de las Pymes, el desarrollo de nuevos yacimientos de empleo, el incremento del capital humano y la orientación a grupos específicos que se encuentran en situación de desventaja en el mercado laboral. En detalle, Ibídem. (pp. 142-147).

${ }^{123}$ El propio Libro Blanco puso de manifiesto que “donde ha existido una mayor convergencia en las respuestas de los Estados miembros es en que las medidas adoptadas se han dirigido generalmente más a reducir el desempleo que a aumentar el empleo. Esto queda reflejado en los numerosos programas de empleo y formación creados para los desempleados, y en los incentivos específicos para fomentar la contratación de determinados grupos”. Ibídem. (p. 140).

124 Ibídem. (p. 141).

125 En mayor detalle sobre las cinco áreas de actuación definidas, Blanpain, R. (2006). European Labour Law.

Netherlands: Kluwer Law International. (pp. 247-248); Watson, P. (2009). Op. Cit. (pp.139-141).

${ }^{126}$ Rogowski, R. (2008). The European Social Model and the law and policy of transitional labour markets in the European Union. En The European Social Model and Transitional Labour Markets. England: Ashgate Publishing Limited. (p. 13).

${ }^{127}$ Con carácter general, sobre su contenido social, véase Blanpain, R. (2006). Op. Cit. (pp. 249-252).

${ }^{128}$ Nogueira Guastavino, M. (2012). Op. Cit. (p. 39); Pons Carmena, M. (2015). Op. Cit. (p. 45).

${ }^{129}$ Acerca de la incorporación del Acuerdo de Política Social al texto del Tratado, Sempere Navarro, A.V. y Pérez Campos, A.I. (2000). El lugar de la política social comunitaria. Revista Noticias de la Unión Europea, 186. (pp. 133-138).

Sobre la misma cuestión, así como de la extensión de la competencia comunitaria y de la regla de la mayoría cualificada, Galantino, L. (2001). Op. Cit. (pp. 47-49).

130 Thüsing, G. (2013). European Labour Law. Germany: C.H. Beck, Hart \& Nomos. (p. 6).

${ }^{131}$ En palabras de Rodríguez-Piñero Royo, “el Tratado de Ámsterdam supone un importante avance en la dirección de incluir la política social dentro del esquema normativo del proceso de integración europea, haciéndolo además al más alto nivel, el que se suele llamar de la <<Constitución Europea>>, su Derecho originario”. Rodríguez-Piñero Royo, M.C. (1998). Los aspectos sociales del Tratado de Ámsterdam. En Aragón Medina, J. (Coord.). Euro y Empleo. Madrid: Colección de Estudios. Consejo Económico y Social. (p. 71). Por su parte, Torrents Margalef señala como principal aportación del Tratado de Ámsterdam en el ámbito social "la composición de la muy preocupante fractura que venía sufriendo el Derecho social comunitario desde que el Reino Unido se opuso y se desvinculó del Protocolo Social anejo al Tratado de Maastricht". Torrents Margalef, J. (2000). La merecida normalización de la política social comunitaria. Revista Documentación Laboral, 61. (p. 115). 
${ }^{132}$ Sobre la controversia acerca de los efectos jurídicos del acuerdo, anexo al Tratado, firmado sólo por once de los doce Estados miembros, Pérez de los Cobos Orihuel, F. (1994). Op. Cit. (pp. 84 y ss). En relación con las distintas posturas de los Estados miembros sobre su incorporación al texto del Tratado, Gomis Vidal, P.L. (1999). Op. Cit. (pp. 66-67).

133 Giubonni, S. (2006). Op. Cit. (p. 28). A este respecto, Gutiérrez-Solar destaca el papel de apoyo y complemento de las instituciones comunitarias en materia social y llama la atención sobre la iniciativa comunitaria en la adopción de Directivas en materia laboral "lo que demuestra que el papel prioritario de los Estados nacionales en materia de política social no implica que las funciones comunitarias hayan de ir a remolque de las decisiones de los Estados en esta materia". Gutiérrez- Solar Calvo, B. (2000). Op. Cit. (p. 161). Palomino Saurina señala que "manteniendo la competencia de los Estados miembros sobre la política de empleo, refuerza notablemente el enfoque comunitario de manera global, proponiendo una estrategia coordinada para el empleo". Palomino Saurina, P. (2013). Op. Cit. Por su parte, Alonso García llama la atención sobre el esfuerzo que deben desarrollar "tanto los Estados como la Comunidad" para "desarrollar una estrategia coordinada para el empleo". Alonso García, B. (2002). El empleo en la Unión Europea y las acciones del Fondo Social. Revista Española de Derecho del Trabajo, 114. (p. 856). Para una visión general sobre las tendencias en las políticas de empleo de los Estados miembros, véase Joly, B. (2005). Politiques de l'emploi en Europe: les grandes tendances chez les voisins de la France.Revista Droit Social, 1. (pp. 12-17).

134 "The fact that an Employment Title was introduced by the Treaty of Amsterdam underlines the fact that unemployment is considered to be the number one social enemy". Blanpain, R. (1999). European Labour Law. The Hague: Kluwer Law International. (p. 156).

135 Así lo considera Gomis Vidal, P.L. (1999). Op. Cit. (p. 37). A modo de síntesis del contenido social del Tratado de Ámsterdam, Galiana Moreno sostiene que la reformas y directrices introducidas por el Tratado de Ámsterdam se condensarían en "a) el reforzamiento de los derechos sociales; b) la ampliación de las competencias del Parlamento Europeo en la adopción de los instrumentos normativos; c) la coordinación de las políticas nacionales de empleo y d) la reunificación del derecho social comunitario". Galiana Moreno, J.M. (1998). Aspectos sociales del Tratado de Ámsterdam. Revista Española de Derecho del Trabajo, 88. (pp. 189-196).

136 “Al margen del destinado con carácter general a la Política Social (con lo que se separan formalmente política social y de empleo)". Ruiz de la Cuesta Fernández, S. (2004). Op. Cit. (p. 540).

137 Con carácter general sobre el nuevo título de empleo del Tratado de Ámsterdam, véase Rodríguez-Piñero Royo, M.C. (1998). Op. Cit. (pp. 85-91); Gomis Vidal, P.L. (1999). Op. Cit. (pp. 93-135); Nogueira Guastavino, M. (2012). Op. Cit. (pp. 41-43); Arrigo, G. (1998). Il diritto del lavoro dell'Unione europea. Tomo I. Milano: Giuffrè Editore. (pp. 156-162). 138 “El empleo, siendo anteriormente competencia exclusivamente nacional, se configura como una competencia compartida, a partir del principio de subsidiariedad, de tal modo que la real eficacia de una estrategia coordinada para el empleo pasa necesariamente por el desarrollo adecuado de las políticas nacionales de empleo, fijándose las competencias de la UE en torno al fomento de la cooperación interestatal en esta materia, el apoyo y el complemento necesarios con respeto siempre a las competencias propias de los Estados”. Ruiz de la Cuesta Fernández, S. (2004). Op. Cit. (p. 540). En el mismo sentido, López-Romero González señala que "cada país [...] sigue siendo dueño de su Política social, aunque a partir de ahora se sitúe en el contexto de una estrategia coordinada de toda la Comunidad". López-Romero González, M.P. (2003). Op. Cit. (p. 739). En detalle sobre la estrategia europea de empleo, Kerschen, N. y Omarjee, I. (2010). La stratégie européene pour l'emploi: un exemple de rencontre entre une politique européenne et le droit communautaire. Revista Droit Social, 2. (pp. 223-233).

139 Ruiz de la Cuesta Fernández, S. (2004). Op. Cit. (pp. 540-541).

140 Sobre la reiterada presencia en el Tratado del objetivo de un alto nivel de empleo, Rodríguez-Piñero Royo, M. y Castellano Burguillo, E. (2001). Op. Cit. (p. 28): “En términos generales, puede decirse que el empleo se constituye como una de las prioridades fundamentales de la Unión en el Tratado de Ámsterdam, apareciendo reflejada esta preocupación una y otra vez a lo largo de su articulado y del extenso paquete de anexos que lo acompaña". ${ }^{141}$ En detalle, Rodríguez-Piñero Royo, M.C. (1998). Op. Cit. (pp. 76-80). 
${ }^{142}$ Publicada en el DOCE 18/12/2000 (2000/C 364/01), pero con ciertas controversias acerca de sus efectos jurídicos. Como recuerda Pons Carmena, "que fuera proclamada formalmente por el Parlamento Europeo, el Consejo y la Comisión no significaba que obtuviera valor jurídico de ningún tipo". Pons Carmena, M. (2015). Op. Cit. (p. 71). En la misma dirección, Rojo Torrecilla señala que "existen numerosas dudas respecto a su consiguiente grado de vinculación y obligatoriedad para todos los poderes públicos y la ciudadanía”. Rojo Torrecilla, E. (2001). La Carta de Derechos Fundamentales de la Unión Europea y los derechos de información y consulta. Revista Temas Laborales, 59. (p. 46). Sobre el contexto económico, político e institucional en el que surgió, así como sus efectos jurídicos, Bercusson, B. (2009). Op. Cit. (pp. 198- 205). Con carácter general, sobre su efectividad y contenido, véase también De la Villa Gil, L.E. (2001). La Carta de los Derechos Fundamentales de la Unión Europea. Revista del Ministerio de Trabajo y Asuntos Sociales, 32. (pp. 13-34). En concreto, sobre su contenido social, véase Herreros López, J.M. (2004). El contenido social de la Carta de los Derechos Fundamentales. Boletín Jurídico de la Universidad Europea de Madrid, 7. (pp. 8-16); Ballester Pastor, M.A. (2009). Los derechos sociales en la Carta Comunitaria de derechos fundamentales y en el Tratado de Lisboa. Revista Actualidad Laboral,15.; Neal, A.C. (2004). Fundamental Social Rights in the European Union: "floor of rights" or "drift to the bottom? En Neal, A.C. (Ed.). The Changing Face of European Labour Law and Social Polic. La Haya: Kluwer Law International. (pp. 72-76).

143 DO 10/03/2001.

${ }^{144}$ En detalle, Zachert, U. (2002). Los derechos fundamentales de los trabajadores en la Carta Europea de Derechos Fundamentales. Revista Temas Laborales, 65. (pp. 22-25).

${ }^{145}$ Bercusson, Clauwaert y Schömann limitan sus efectos a los de una mera declaración política. Bercusson, B., Clauwaert, S.y Schömann, I. (2006). Legal prospects and legal effects of the EU Charter. En Bercusson, B. (Ed.). European Labour Law and the EU Charter of Fundamental Rights. Germany: Nomos. (p. 42). Por su parte, Herreros López señala que "los derechos integrados en la Carta no gozan de otra protección que la mera recomendación que, en su caso, pueda dirigir el Comité de Ministros del Consejo de Europa, previa mayoría cualificada de dos tercios de sus miembros, al Estado presumiblemente vulnerador de la Carta”. Herreros López, J.M. (2004).Op. Cit. (p. 8). No obstante, Miranda Boto destaca el valor creciente de la Carta de los Derechos Fundamentales de la Unión Europea a través de los pronunciamientos del Tribunal de Justicia de la Unión Europea y Sánchez-Rodas Navarro llama la atención sobre su carácter de Derecho originario en virtud del artículo 6.1 del Tratado de la Unión Europea que equipara su valor jurídico al de los Tratados. Miranda Boto, J.M. (2017). El derecho social de la Unión Europea en la encrucijada: entre la parálisis legislativa y el impulso judicial. Revista del Ministerio de Empleo y Seguridad Social, 127. (pp. 30 y ss.); Sánchez-Rodas Navarro, C. (2018). Sobre la (in)competencia de las instituciones europeas para reformar los sistemas públicos de pensiones nacionales a la luz de la UE y de los Tratados Internacionales. Cuadernos de Derecho Transnacional, Vol. 1, 1. (p. 396).

${ }^{146}$ Martínez Yáñez, N.M. (2020). La Carta de Derechos Fundamentales de la UE y los derechos profesionales de los trabajadores autónomos. Revista Temas Laborales, 151. (p. 111).

${ }^{147}$ En opinión de Nogueira Guastavino "la virtualidad de la Carta reside en haber reunido por primera vez en un único documento todos los derechos que hasta ahora se dispersaban en distintos instrumentos legislativos [... ]". Nogueira Guastavino, M.(2012). Op. Cit. (p. 44).

${ }^{148}$ Socially no so nice". Blanpain, R. (2006). Op. Cit. (p. 257). En mayor profundidad sobre las modificaciones de carácter social introducidas por el Tratado de Niza, véase Pons Carmena, M. (2015). Op. Cit. (pp. 79-84).

149 Pedrosa Sanz, R. (2009). Op. Cit. (pp. 618-619).

${ }^{150}$ A propuesta de la Comisión y previa consulta al Parlamento.

${ }^{151}$ Acerca de la aplicación de esta "cláusula pasarela" a los ámbitos contemplados en el artículo 137, Nogueira Guastavino, M. (2012). Op. Cit. (p. 46).

${ }^{152}$ Con una nueva adaptación en el año 2007 en Estrasburgo.

153 Sobre el fracasado Tratado Constitucional de 2004, Pons Carmena, M. (2015).Op. Cit. (pp. 85-89).

$154 \mathrm{DO} \mathrm{N}^{\circ} \mathrm{C} 306,17 / 12 / 2007$.

155 En sustitución del Tratado Constitutivo de la Comunidad Europea.

${ }^{156}$ Para una aproximación general a las novedades en materia social del Tratado de Lisboa, Pons Carmena, M. (2015).Op. Cit.(pp. 101-106); Schmitt, M.(2010). La dimensión sociale du traité de Lisbonne. Revista Droit Social, 6. (pp. 682-695). 
157 Martín Valverde, A. y Miranda Boto, J.M. (2010). El Tratado de Lisboa y el Derecho Social de la Unión Europea. Revista Actualidad Laboral, 19. (p. 6).

${ }^{158}$ Miranda Boto, JM.(2008). La incidencia del Tratado de Lisboa en el ámbito social. Revista Temas Laborales, 97. (pp. 12-15). Con carácter general sobre la delimitación de competencias establecida en el Tratado de Lisboa, véase Tridimas, T. (2012). Competence after Lisbon: The exclusive search for bright lines. En Ashiagbor, D., Countouris, N. y Lianos, I. (Ed.). The European Union after the Treaty of Lisbon. New York: Cambridge University Press. (pp. 47-77).

$159 \mathrm{Ni}$ en el plano social en general "does not introduce any real changes [... ] as far as social rights are concerrned", centrándose en cambios organizacionales "changes are organizational in their nature and reductive rather than substantive" e institucionales "institutional changes have been made to the functioning of the European Union with regards to settting minimal standards for social and political protection". Swiatkowski, A.M. (2009). European Union citizenschip and the rights of access for welfare State: a comparison with welfare rights guaranteed by the Council of Europe as seen from the perspective of a new member State. En Neergaard, U., Nielsen, R. y Roseberry, L.M.(Eds.). Integrating welfare functions into EU Law. From Rome to Lisbom. Copenhagen: DJOF Publishing. (p. 123).

160 Martínez Yáñez, N.M. (2011). La coordinación de las políticas de empleo a la luz del Tratado de Lisboa. Revista del Ministerio de Trabajo e Inmigración, 92. (p. 331): "Las competencias en materia de empleo siguen siendo las mismas desde que el Tratado de Amsterdam introdujese un sistema de coordinación liderado por las instituciones comunitarias. Es decir, los Estados miembros conservan intacta su soberanía en materia de empleo, pero al mismo tiempo se ven obligados a seguir las directrices marcadas por la Unión Europea, a fin de que sus políticas de empleo se articulen en torno a unos principios y objetivos comunes".

${ }^{161}$ En detalle sobre el tratamiento de las competencias económicas, de empleo y sociales en el artículo 5 del TFUE. Ibídem.(pp. 330-335).

162 "Esta política social, y a falta de definición expresa, se entiende como aquello que engloba el fomento del empleo, la mejora de las condiciones de vida y de trabajo, una protección social adecuada, el diálogo social, el desarrollo de los recursos humanos para conseguir un nivel de empleo elevado y duradero y la lucha contra las exclusiones [... ]". Hierro Hierro, F.J.(2019). La protección social en la Unión Europea. En Cardenal Carro, M. y Pérez Campos, A.I. (Dirs.). Areta Martínez, M. (Coord.). Derecho del trabajo y protección social en la Unión Europea: situación actual y perspectivas de futuro. Madrid: Dykinson. Servicio de Publicaciones de la URJC.(p. 192).

163 Martínez Yáñez, N.M. (2011). Op. Cit. (pp. 327-330).

164 "Sin que ello implique atribución de competencia alguna a la Unión en esta materia". Martín Valverde, A. y Miranda Boto, JM.(2010). Op. Cit. (p. 7).

${ }^{165}$ Mientras que Nogueira Guastavino habla de un derecho de "re-examen" de este tipo de actos legislativos, Dans Álvarez de Sotomayor habla de un “poder de veto" y Bilbao Ubillos de una "cláusula de salvaguardia”. Nogueira Guastavino, M. (2012). Op. Cit. (p. 50); Dans Álvarez de Sotomayor, L.(2011). La libre circulación de personas tras el Tratado de Lisboa. Revista del Ministerio de Trabajo e Inmigración, 92. (p. 279); Bilbao Ubillos, J.(2009). El Tratado de Lisboa y la regulación básica de la cuestión económica y social en la Unión Europea. En Matía Portilla, F.J.(Dir.).Estudios sobre el Tratado de Lisboa. Granada: Editorial Comares. (p. 120).

166 Pedrosa Sanz, R.(2009). Op. Cit. (p. 620).

167 "The only role to be acknowledged for labour law is ancillary". Sciarra, S. (1995). Social Values and the Multiple Sources of European Social Law. European Law Journal, Vol. 1, 1. (p. 65).

${ }^{168}$ No obstante, Blázquez Agudo llama la atención sobre la necesidad de no desatender lo social para lograr lo económico. Sobre su necesaria interrelación, véase Blázquez Agudo, E.M. (2006). El futuro de la libre circulación de trabajadores. Repensando su contenido a partir de la Directiva Marco sobre mercado interior. Revista del Ministerio de Trabajo y Asuntos Sociales, 62. (pp. 111-113).

${ }^{169}$ Como señala García Murcia "no se advierte aún como terreno practicable para una intervención directa por parte de la Comunidad, entre otras razones por su intenso enraizamiento en las políticas nacionales”. García Murcia, J. (2004). Op. Cit. (p. 57).

${ }^{170}$ Nielsen, R. (2013). EU Labour Law. Copenhagen: DJOF Publishing. (p. 48). 